\title{
INTEGRATED GEOPHYSICAL EXPLORATION OF A KNOWN GEOTHERMAL RESOURCE: NEAL HOT SPRINGS
}

\author{
by \\ Clinton Ryan Colwell
}

\author{
A thesis \\ submitted in partial fulfillment \\ of the requirements for the degree of \\ Master of Science in Geophysics \\ Boise State University
}

December 2013 
(c) 2013

Clinton Ryan Colwell

ALL RIGHTS RESERVED 


\title{
BOISE STATE UNIVERSITY GRADUATE COLLEGE
}

\section{DEFENSE COMMITTEE AND FINAL READING APPROVALS}

\author{
of the thesis submitted by
}

\author{
Clinton Ryan Colwell
}

Thesis Title: Integrated Geophysical Exploration of a Known Geothermal Resource: Neal Hot Springs

Date of Final Oral Examination: $\quad 11$ July 2013

The following individuals read and discussed the thesis submitted by student Clinton Ryan Colwell, and they evaluated his presentation and response to questions during the final oral examination. They found that the student passed the final oral examination.

Lee M. Liberty, M.S. Chair, Supervisory Committee

Kasper van Wijk, Ph.D. Member, Supervisory Committee

Patrick Ian Warren, Ph.D. Member, Supervisory Committee

The final reading approval of the thesis was granted by Lee M. Liberty, M.S., Chair of the Supervisory Committee. The thesis was approved for the Graduate College by John R. Pelton, Ph.D., Dean of the Graduate College. 


\section{ACKNOWLEDGMENT}

I owe thanks to a number of people for helping to realize this goal of mine. I would like to thank Lee Liberty for his guidance and help with all of my writing, presenting, and interpretations over the last two years. He kept me positive through his own positivity and encouraging words. Kasper van Wijk deserves my gratitude for all his help in the field and consummate support and advice. Ian Warren, I thank you for taking time out of your busy schedule to be part of my committee and for all of the information about Neal Hot Springs. Thank you Jonathan Glen, your expertise was astounding, and I am so grateful for all of your help. Thank you Mila Adam for mentoring the "Thermal Thinkers". Dan Shaltry, thank you for your help in the field, and for working with the passive seismic data to isolate fault activity. I owe thanks to Celina Suarez for helping proof read and edit all of these words on the ensuing pages. I need to thank my office mate, Shaun Finn for hearing my ideas and providing geologic and geophysical advice throughout the last years. Joel Edwards, your geologic expertise of Neal Hot Springs and friendship proved invaluable. As in all I do, without the support and love of my family this thesis would have never happened. Thank you Mom, Dad, Jesse, Jim, and Scot. Finally, I would like to thank all of the people who helped with data collection and or logistics of the numerous trips out to the field.

These include Hank Hetrick and the students and professors of the 2011 Boise State University, Colorado School of Mines, and Imperial College of London field camp. 


\section{ABSTRACT}

I present an integrated geophysical characterization of the Neal Hot Springs geothermal system in eastern Oregon. This newly established $23 \mathrm{MW}$ geothermal production site is located in a region of complex geology and intersecting faults associated with two major extensional systems; the Oregon-Idaho Graben and the western Snake River Plain. The intersection of two dominant fault orientations, coupled with a high geothermal gradient from relatively thin continental crust and radioactive decay from a shallow granitic body, produces the pathways and heat needed for deep water circulation at Neal Hot Springs. New geologic mapping, geochemistry, and measurements from several boreholes in the area suggest a normal fault dips to the southwest to form a half-graben basin. This basin-bounding fault, termed the Neal Fault, serves as the primary conduit for deep water circulation. Potential field, electrical, and seismic data characterize this major fault along with other structures in the area. A self-potential survey indicates that water is upwelling in the fault zone, and suggests that the fault provides the means for heated water to migrate to the surface. Electrical and magnetic surveys offer methods to locate hydrothermal waters within 0.5 $\mathrm{km}$ of ground surface and at the surface. Gravity models help integrate and refine my interpretations of the geologic structures. I then use tectonic faulting as a proxy for permeability to form a comprehensive three-dimensional subsurface permeability model of Neal Hot Springs. This integrative geophysical approach is not typical in geothermal exploration and offers to improve costs related to exploration in complex geologic environments. 


\section{TABLE OF CONTENTS}

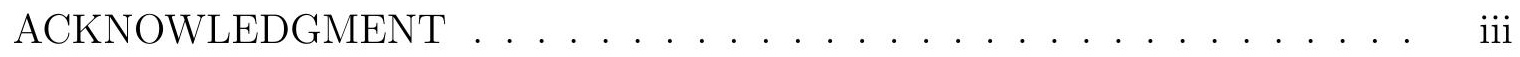

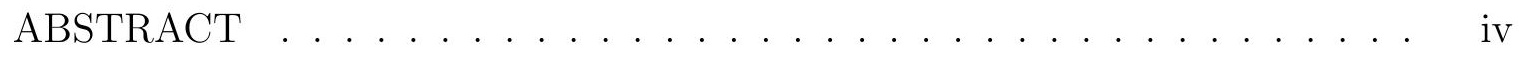

LIST OF FIGURES . . . . . . . . . . . . . . . vii

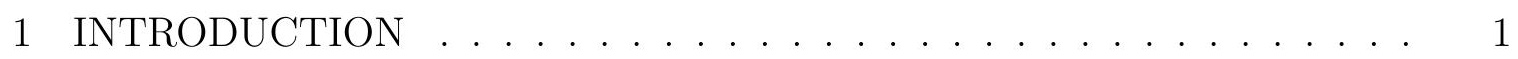

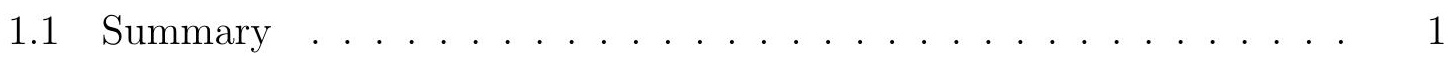

1.2 Introduction . . . . . . . . . . . . . . . 2

2 GEOLOGICAL AND GEOPHYSICAL SETTING $\ldots \ldots \ldots$

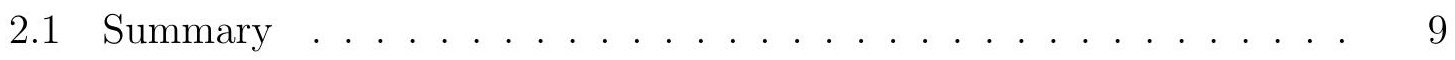

2.2 Regional Geology . . . . . . . . . . . . . . . . . . 10

2.3 Regional Geophysics . . . . . . . . . . . . . . . . 18

2.4 Local Geology at Neal Hot Springs . . . . . . . . . . . . . . . 19

3 METHODS . . . . . . . . . . . . . . . . . . . . . . 29

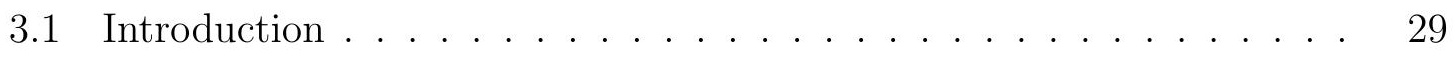

3.2 Gravity and Magnetic Methods . . . . . . . . . . . . . . 29

3.2 .1 Gravity Methods . . . . . . . . . . . . . . . . . . . 29

3.2 .2 Magnetic Methods . . . . . . . . . . . . . . . 37

3.3 Seismic Methods . . . . . . . . . . . . . . . . . . . . 41

3.4 Electrical Methods . . . . . . . . . . . . . . . . 47

3.4.1 Direct Current Resistivity . . . . . . . . . . . . 47 
3.4 .2 Self-Potential . . . . . . . . . . . . . . . . . 50

3.4.3 Controlled Source Audiomagnetotellurics . . . . . . . . . . . 53

4 DISCUSSION $\ldots \ldots \ldots \ldots \ldots \ldots \ldots \ldots \ldots$

4.1 Introduction . . . . . . . . . . . . . . . . . 58

4.2 Geophysical Data Integration $\ldots \ldots \ldots \ldots \ldots$

4.3 Gravity Modeling . . . . . . . . . . . . . . . . . . 63

4.4 Three Dimensional Subsurface Model . . . . . . . . . . . . . . . . 65

4.5 Regional Implications . . . . . . . . . . . . . . . . . . 66

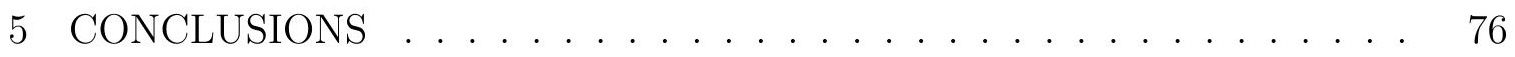

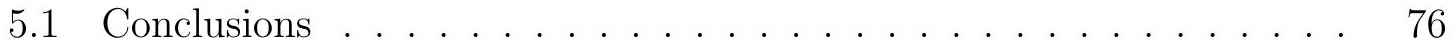

5.2 Future Work . . . . . . . . . . . . . . . . . . . 77

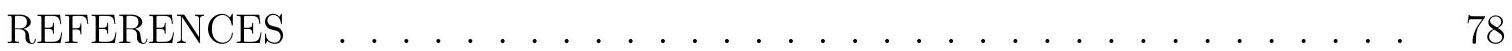




\section{LIST OF FIGURES}

1.1 Total U.S. energy consumption as a percentage of each resource (Tester et al., 2006). . . . . . . . . . . . . . . .

1.2 Generalized cross section through a geothermal system. For a magmatic system, the water would be heated by a shallow magmatic body. A structurally controlled system must have deeply penetrating faults which allow for heated waters to rise. . . . . . . . . . . . .

1.3 Neal Hot Springs geothermal field in eastern Oregon. Neal Hot Springs is roughly 26 kilometers west of Vale, Oregon at the terminus of the western Snake River Plain (WSRP). The nearby and recently active Cottonwood Mountain fault $(\mathrm{CMF})$ is shown just east of Neal Hot Springs. The Hope Butte Quadrangle is highlighted by a black rectangle. 8

2.1 Location of NHS geothermal field in eastern Oregon after Cummings et al. (2000). NHS lies at western margin of the stable North American Craton within the intersection and overlap of a number of large tectonic events during the last eighteen million years as shown above. Captions and colors: Northern Nevada Rift- NNR; western Snake river Plaintan; Columbia River Flood Basalt Group- light grey; Basin and Rangedark grey; Chief Joseph dike swarm (CJ)- brown; Inferred cratonic margin is located at the $S r_{87} / S r_{86} .706$ line which is a blue dashed line. 13 
2.2 Aeromagnetic anomaly map of the intermountain west of the United States after Glen and Ponce (2002). NHS is shown as a black star. The maroon circle is the radius of the Yellowstone mantle plume as it flattens under the continental lithosphere at seventeen million years before present, with its center near NHS (Shervais and Hanan, 2008). The large spoke-like fractures of the Northern Nevada Rift (NNR) appear as magnetic highs, and also suggest a point near NHS may have been the center of the Yellowstone plume (Purple hexagon) (after Glen and Ponce, 2002) . . . . . . . . . . . . . . . . .

2.3 Crustal thickness in eastern Oregon from seismic receiver function analysis after Eagar et al. (2011). Note the thin crust of less than thirty kilometers beneath NHS. The thin nature of the crust provides an explanation for the high heat flow values in eastern Oregon and a potential heating mechanism for NHS (Blackwell, 1978). . . . . . . . .

2.4 Heat flow data from the Southern Methodist University National Heat Flow Database. The crust around NHS (black star within orange circle) exhibits high heat flow values that are more than twice the national average (Wisian et al., 2000). These high heat flows are coincident with a thinned region of crust beneath NHS (Figure 2.3) . . . . .

2.5 Regional gravity data and gravity stations of eastern Oregon and western Idaho (Kucks, 1999). The large gravity high outlined by normal faults above likely represents the extent of graben filling volcanism associated with the Oregon-Idaho Graben. . . . . . . . . . . 
2.6 Regional magnetic data eastern Oregon and western Idaho (Bankey et al., 2002). The maxima of the horizontal gradients (HGM) are plotted as maroon dots. These locations indicate subsurface magnetic contacts (Phillips, 1997b). By following the trend of the HGM a fault is interpreted northeast of NHS which follows the trend of the Vale fault Zone and bounds a large basin (Lawrence, 1976). This is likely an expression of the Cottonwood Mountain fault (Personius, 2002). .

2.7 GPS geodetic data in eastern Oregon and Idaho after Payne et al. (2012). Clockwise rotation of the Pacific Northwest relative to stable North America is accommodated along the Olympic Wallowa Lineament (OWL) (McCaffrey et al., 2007). Payne et al. (2012) suggest that a rapid decrease in velocity at the western margin of the western Snake River Plain leads to an area of compression north NHS. For an explanation of the other labels please see Payne et al. (2012). . . . . .

2.8 Digital elevation model of NHS showing the location of boreholes and the geothermal power plant (Image taken from GeoMapApp) (Ryan

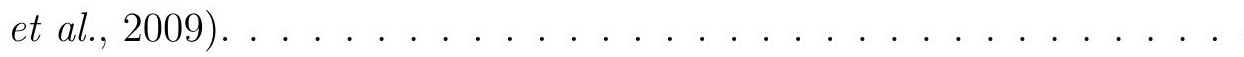

2.9 Geologic map of the NHS geothermal area with the black star representing NHS (Edwards, 2013). . . . . . . . . . . . . . .

2.10 Map of NHS highlighting major structures immediately surrounding NHS mapped by Edwards (2013). Balls indicate a normal fault, with the ball on the hanging wall. The dashed lines are the location of inferred faults. . . . . . . . . . . . . . . 
2.11 Stratigraphy at NHS from Edwards and Faulds (2012). Note that the Jurassic basement granite of the Olds-Ferry-Izee Terrane is not shown. 28

3.1 Location of geophysical surveys at NHS. Yellow lines are ground magnetic surveys, grey dots are gravity stations, dark green and light green lines are Vibroseis lines 1 and 2 respectively, red line is a hammer seismic line, blue line is self-potential and direct current resistivity, and purple marks a controlled source audiomagnetotelluric station. This color scheme will be continued throughout this thesis. . . . . . . . .

3.2 The Complete Bouguer Anomaly map of NHS. Note the small variations in the field and slightly pockmarked appearance. These features were removed with matched filtering. The bottom graph depicts the radially averaged power spectrum versus wavenumber, and my linear fits to the spectrum for matched filtering as blue lines. . . . . . . . .

3.3 Top image shows the short wavelength, high frequency content after filtering, while the bottom is the longer wavelength. Note the small range (.8 milliGal) of the short wavelength content, and the correlation between gravity stations and noise. Subsequent processing and interpretation is made on the longer wavelength content with the noise removed. . . . . . . . . . . . . . . . . 
3.4 Filtered gravity overlain on a topographic map of NHS. Gravity stations are shown as grey dots. The maxima of the Horizontal Gradient Method (Blue dots), and maxima of the Analytic Signal (Maroon dots) are shown (Blakely and Simpson, 1986; Roest et al., 1992). These suggest subsurface density contacts and are interpreted as faults. Dip directions for interpreted faults are also shown by arrows and were interpreted from overlaying the maxima of the Analytic Signal and Horizontal Gradient Method (Phillips, 1997b). The sudden eastward change in strike of the Neal fault is questionable, as no AS locations nor topography suggest a westerly dipping structure. Therefore this feature is highlighted with a dashed line. The circular feature to the west shows a continuous HGM and could likely be geologic. . . . . . .

3.5 TMI map of NHS with magnetic stations shown in black. Interpreted steepest gradients that show similar anomaly shape and continue through multiple lines are interpreted as faults and are shown in green. Grey lines are density contacts located with gravity data. . . . . . . . . . 42 
3.6 TMI map of the surface springs at NHS with magnetic stations shown in black. This survey is roughly the size of the orange circle in the inset. The springs fall within a magnetic high. This anomaly is suggestive of geochemical conditions that are preserving and/or creating magnetic minerals. This is an oddity in that many geothermal fields exhibit a magnetic low over the geothermal site from geothermal water degradation of magnetic minerals ((Cumming, 2009; Hunt et al., 2009)). The strong dipolar anomaly in the southwest is caused by a small building. . . . . . . . . . . . . . . . . . .

3.7 Seismic processing flowchart showing steps used in processing seismic data at NHS after Yilmaz (2001). . . . . . . . . . . . . 48

3.8 Vibroseis line 1. The Hope Butte, Cottonwood Mountain, and Bully faults have been interpreted and are shown above. The profile location

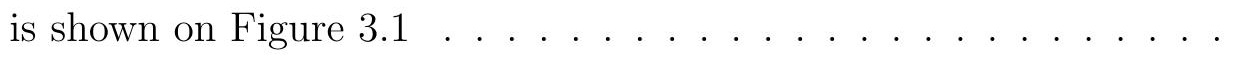

3.9 Vibroseis line 2. I interpret a small offset in the Neal Basalt as the Cottonwood Creek fault. The profile location is shown on Figure 3.1 .

3.10 Hammer seismic line with the interpreted Neal fault. The line location is shown on Figure 3.1. . . . . . . . . . . . . . . . . . 
3.11 (Top) Self-Potential line across the surface springs at NHS. A 40 milliVolt positive anomaly over the springs suggest upwelling water along the Neal fault. The amplitude of this anomaly coincides with other selfpotential studies of geothermal systems (Corwin and Hoover, 1979). (Bottom) Direct-current resistivity profile that follows the same line as the self-potential line. The juxtaposition of highly resistive material against low resistivity material is interpreted as the Neal fault placing resistive volcanics against a zone of geothermal waters that have migrated upward to the surface along the fault. . . . . . . . . .

3.12 Skin depth $(\delta)$ as a function of ground resistivity $(\rho)$ and frequency $(f)$ from Zonge and Hughes (1991). Note that for NHS data, a frequency of 16 hertz and ground resistivity of about $20 \Omega \cdot m$ makes for a skin depth of 500 meters. . . . . . . . . . . . . . .

3.13 Apparent resistivity pseudosection for the frequencies between 16 and 8192 hertz. The location of this line is shown in Figure 3.1. . . . . . 
3.14 Inverted resistivity pseudosection for the frequencies between 16 and 8192 hertz. The Neal fault is interpreted at the intersection of extreme low resistivity and moderate resistivity Hog Creek volcanics on the western edge of the map. The zone of low resistivity to the west is caused by geothermal water infiltration into the down-dropped Hog Creek sequence. This infiltration has done one of two things. Either the volcanics have been altered into a highly conductive clay cap on top of the geothermal reservoir, or geothermal waters are directly being imaged as they migrate laterally through the brecciated Hog Creek sequence. This low resistivity zone is overlain by more resistive sediments. 57

4.1 The NHSR with the locations for all the geophysical methods broken down into western and eastern sections. Modelled gravity profiles are shown as A-A' and B-B' with the final three-dimensional model's outline shown with a tan dashed line. . . . . . . . . . . . 68

4.2 Interpreted vibroseis, gravity and magnetic datasets within the eastern

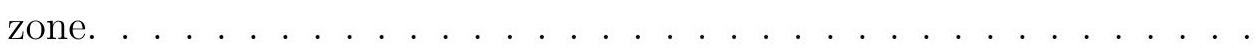

4.3 Interpreted hammer seismic, gravity, magnetic, and CSAMT datasets within the western zone. . . . . . . . . . . . . . 70

4.4 Gravity model A to A'. The original model tested is shown on top, with the lower model being my final interpretation. . . . . . . . . . . 71

4.5 Gravity model B to B'. The original model tested is shown on top, with the lower model being my final interpretation. . . . . . . . . . . 72

4.6 An overview map of the NHSR depicting my major structural and geologic interpretations. . . . . . . . . . . . . . . 
4.7 The final three-dimensional subsurface model for the NHSG showing borehole locations and faults as a proxy for permeability. . . . . . . . 74

4.8 The three-dimensional subsurface permeability model at the NHSG as seen from below the surface. . . . . . . . . . . . . . . . . 75 


\section{CHAPTER 1: INTRODUCTION}

\subsection{Summary}

Geothermal power production is a growing industry that is hampered by high development costs. One reason for these high costs is the large risk in developing a geothermal field due to a limited understanding of permeability, temperature, and fluid distribution within the geothermal system. My approach to reducing the price of geothermal development involves an integrated geophysical campaign involving numerous imaging techniques to constrain subsurface permeable pathways, and the temperature and fluid distribution. I suggest that my approach will help geothermal energy exploration by providing subsurface information that is critical for sustainable development. The Neal Hot Springs geothermal field is a geothermal energy resource operated by U.S. Geothermal Incorporated. My results provide the geological and hydrogeological framework needed to reduce the cost and uncertainty related to geothermal well placement by isolating subsurface permeability zones. This uncertainty in well placement represents the major expense of the exploration and development phases for any geothermal field. I propose that the integration of multiple geophysical methods into geothermal exploration is an economically feasible contributor to the expansion of geothermal energy use. 


\subsection{Introduction}

The United States relies on hydrocarbons for over $70 \%$ of its total energy needs (Department of Energy, 2012). This dependence has raised numerous worries about national defense, environmental impacts, reliance on foreign hydrocarbon sources, and long term energy sustainability. A recent push for developing cleaner energy resources stems from these concerns (e.g., Tester et al., 2006). Many new energy technologies such as wind and solar, are ephemeral and rely on forces which are neither constant nor predictable. Unlike solar or wind energy sources, geothermal energy provides a constant flow of electricity in any weather and at any time of day. When compared to fossil fuel sources, geothermal energy can reduce carbon dioxide emissions by more than 50\% (Fridleifsson et al., 2008). Currently, geothermal energy does not play a major role in national energy consumption, generating less than one percent of the energy produced (Figure 1.1) (e.g., Tester et al., 2006). This production amount represents only a small fraction of the known geothermal reserves. In a 2006 study led by MIT, geothermal energy was highlighted as a potential major energy producer by 2050 (Tester et al., 2006). The report suggests that an energy output of greater than 100 gigawatts of electricity would be possible with the proper investment in research and development, which is over one-tenth of the current U.S. energy needs.

Geothermal systems fall into two geologic categories, magmatically driven or structurally driven systems (e.g., Wisian and Blackwell, 2004). Magmatic systems rely on a subsurface magma body to provide a heating mechanism for geothermal waters, while structurally driven systems rely on elevated geothermal gradients to drive heated waters near the surface for shallow heat extraction (Curewitz and Karson, 1997; Delvaux et al., 2010; Faulds et al., 2011). Thermal buoyancy is thought to spur the ascension 


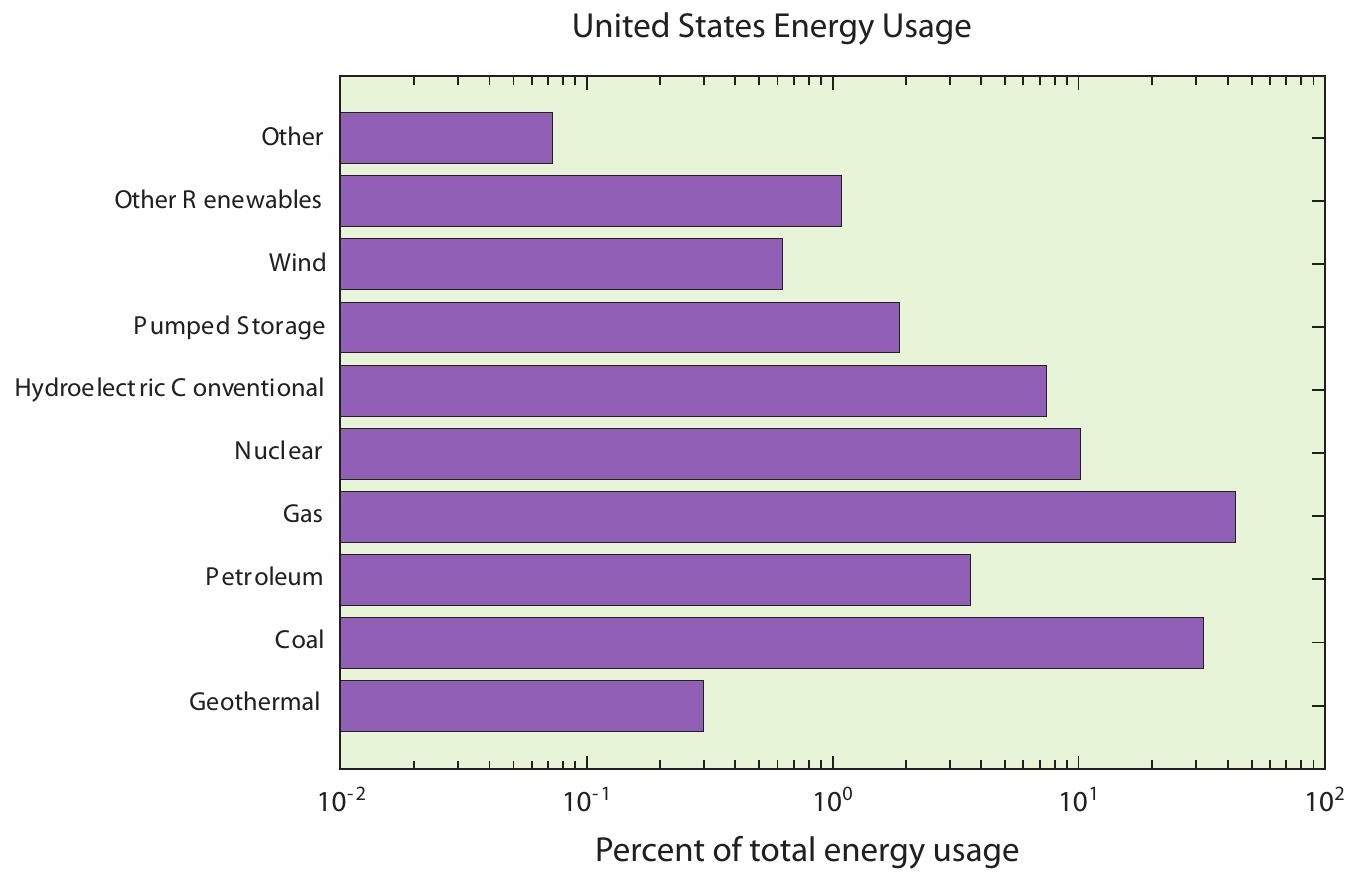

Figure 1.1: Total U.S. energy consumption as a percentage of each resource (Tester et al., 2006). 


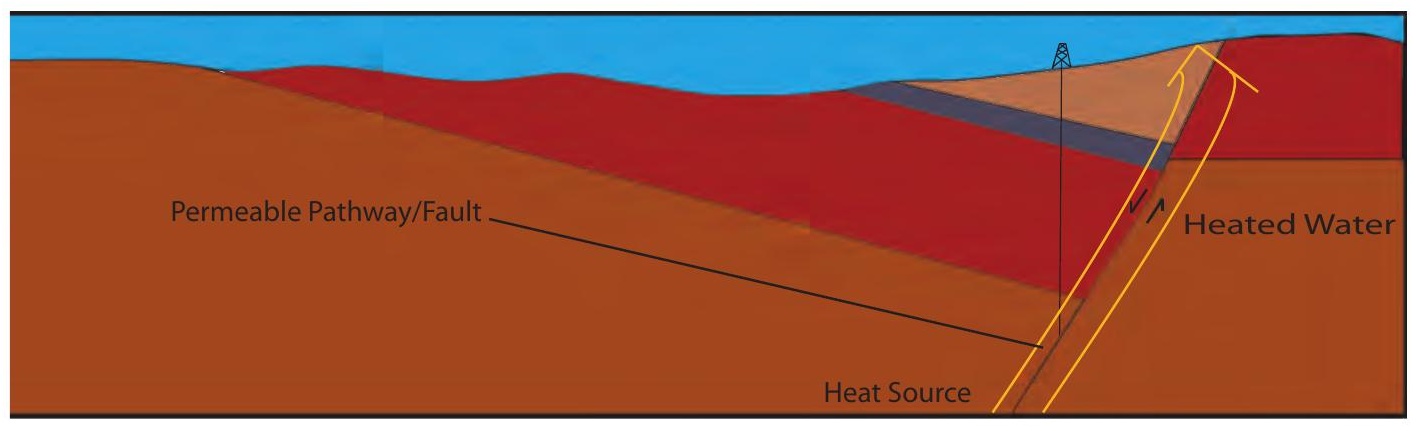

Figure 1.2: Generalized cross section through a geothermal system. For a magmatic system, the water would be heated by a shallow magmatic body. A structurally controlled system must have deeply penetrating faults which allow for heated waters to rise.

of heated waters to the surface or shallow subsurface via fractures or faults where they are tapped for differing geothermal applications (Cumming, 2009). Generally, structurally controlled geothermal systems are associated with steeply dipping active faults that penetrate to great depths (Faulds et al., 2006)(Figure 1.2). Ultimately, the target of any geothermal drilling program is to intersect these permeable zones of hot fluid in the subsurface. The depth at which heated waters can be extracted directly dictates the cost of geothermal production.

The geothermal target zone, which I refer to as the production zone, is generally synonymous with a fault zone (e.g., Curewitz and Karson, 1997). The optimal production zone can be a meter-scale high permeability isolated area often found many hundreds of meters below surface. Due to these two characteristics, finding geothermal production zones is extremely difficult and represents one of the largest challenges in developing a geothermal system (Barbier, 2002). The geothermal industry is burgeoning, but still plagued by high development costs (e.g., Jennejohn, 
2011). One reason for these high costs is the large risk in developing a field due to limited subsurface information that can locate and characterize production zones (e.g., Barbier, 2002). Exploration geophysics has long been used by the hydrocarbon and mineral industries as a means of probing the subsurface for geologic and hydrogeologic information, often combining numerous geophysical methods into a single interpretation. The subsurface inference is then used to identify drilling targets. The reasoning for this approach is to limit one of the most expensive aspects of locating a resource, the necessary amount of drilling, and has been shown by Nissen et al. (2003) to increase drilling success rates by up to 40\%. The geothermal industry is no different, with drilling programs comprising more than $40 \%$ of the total cost of a geothermal power plant (Cross and Freeman, 2009). Surprisingly, the integrated geophysical approach has not crossed over into the geothermal industry as a means for identifying potential permeable zones of geothermal water. Reasons for the restricted use of geophysics are likely due to the lack of studies evaluating the success of an integrated interpretation of numerous geophysical techniques for characterizing geothermal systems, the difficulty of implementing geophysics in the heterogeneous subsurface typical of most geothermal systems, and/or the expensive nature of an integrated geophysical campaign. Blackwell et al. (2002); Bujakowski et al. (2010); Schill et al. (2011) provide some positive examples of using multiple (more than two) geophysical exploration methods in a geothermal setting, but these approaches are far from the ordinary. Normally, fewer than two geophysical methods are employed that do not allow for a confident and comprehensive characterization of the subsurface geometry of the geothermal systems investigated; Long and Kaufmann (1980); Richards et al. (2010); Delvaux et al. (2010); Mundell and Herbert (2010); Rosenkjaer 
and Oldenburg (2012) offer a few of the many cases of less than two geophysical methods used for geothermal energy exploration. The geothermal industry therefore needs more evidence to help determine whether a geophysically sparse or robust approach is effective when exploring for and developing a field.

I propose that by integrating a suite of geophysical techniques, subsurface structure and hydrogeology within a geothermal field can be characterized, and in doing so provide evidence that an integrated geophysical approach is advantageous to any geothermal site for identifying potential permeable zones. U.S. Geothermal Incorporated developed the Neal Hot Springs geothermal field, located in eastern Oregon near the town of Vale, into a 23 megawatt power plant during the course of my research (Figure 2.1)(Figure 1.3). To avoid ambiguity, Neal Hot Springs region (NHSR) will refer to the area within a ten kilometer radius immediately surrounding the surface springs, Neal Hot Springs (NHS) will refer to the surface expression of the springs, while references to the geothermal energy production field at NHS will be regarded as the Neal Hot Springs geothermal field (NHSG). NHSG is ground breaking in that it is the first energy producing geothermal site in Oregon, and the only geothermal power plant in the United States outside the Great Basin that is not magmatically controlled or located along the San Andreas fault system (Edwards, 2013).

Within this thesis I first present the regional geologic and geophysical framework for the NHSR. I follow this framework description with a summary of the local stratigraphy derived from borehole geochemistry and the surface geology of Ferns et al. (1993); Edwards and Faulds (2012); Edwards (2013). My thesis then investigates the subsurface of NHSR in order to identify and characterize subsubsurface permeable zones. To accomplish this goal, I interpret exploration geophysical data 
from the following sources: 1) seismic reflection, direct-current resistivity, and selfpotential geophysical data collected as part of a 2011 Department of Energy (DOE) funded geophysics field camp; 2) gravity data provided by U.S. Geothermal Inc.; 3) controlled-source audiomagnetotelluric (CSAMT) data collected under DOE funding through the 2012 National Geothermal Student Competition; and 4) magnetic data collected after the DOE funded field camp geophysical campaign. My interpretations are then integrated into a single three-dimensional subsurface model of the NHSG that isolates potential permeable zones. Finally, my results are summarized, with conclusions drawn about the subsurface at the NHSG and the potential economic impact of a geothermal exploration and development program driven by a geophysically diverse approach to understanding prospective production zones. 


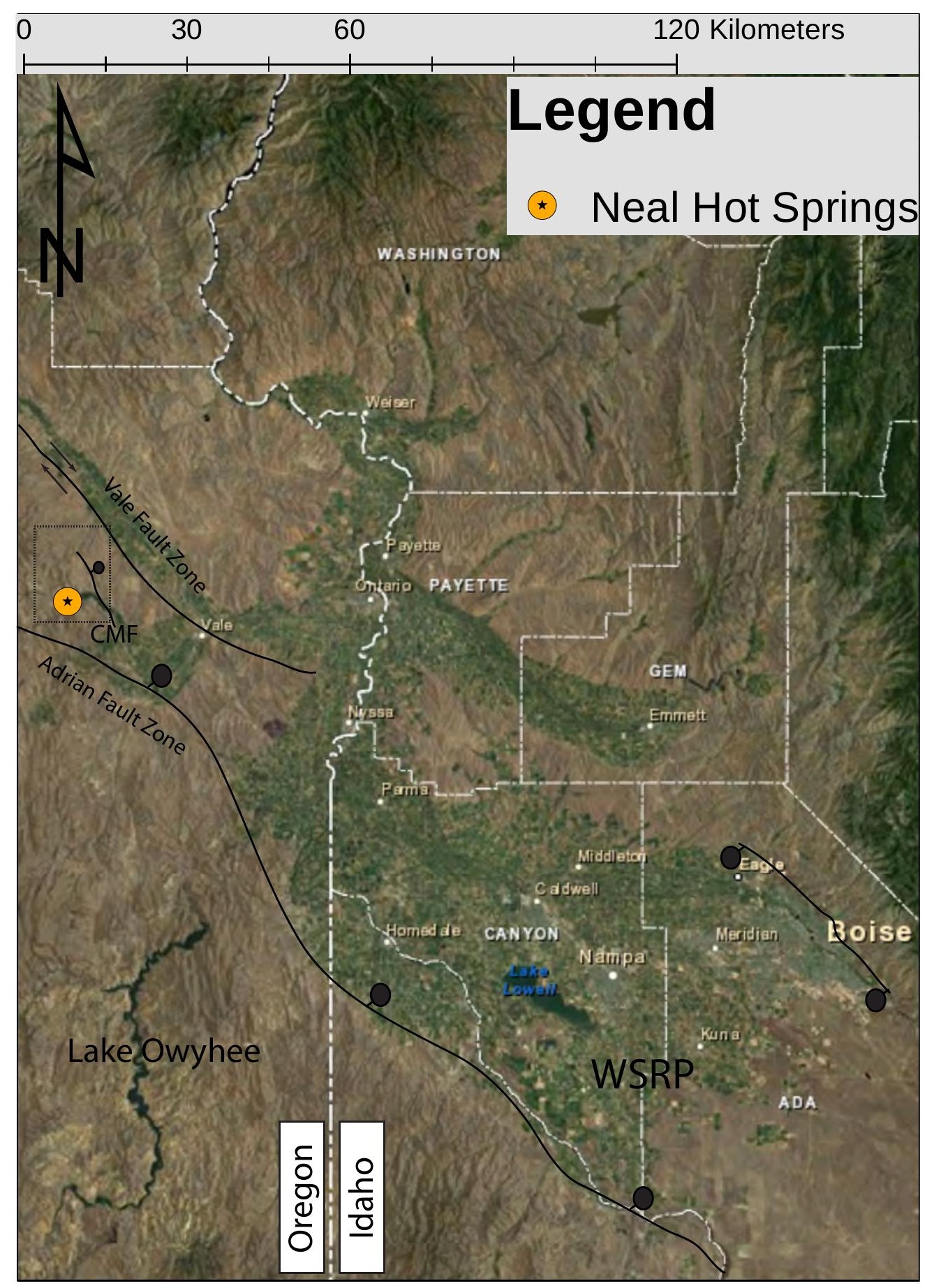

Figure 1.3: Neal Hot Springs geothermal field in eastern Oregon. Neal Hot Springs is roughly 26 kilometers west of Vale, Oregon at the terminus of the western Snake River Plain (WSRP). The nearby and recently active Cottonwood Mountain fault (CMF) is shown just east of Neal Hot Springs. The Hope Butte Quadrangle is highlighted by a black rectangle. 


\section{CHAPTER 2:}

\section{GEOLOGICAL AND GEOPHYSICAL SETTING}

\subsection{Summary}

The NHSR is located in eastern Oregon where Neogene and younger extensional tectonic and magmatic activity has defined much of the geological landscape (Figure 2.1). Yellowstone plume head impingement with the continental lithosphere is thought to have caused mid-Miocene Columbia Flood Basalt volcanism and extension related to the Northern Nevada Rift (NNR) by supplying enormous volumes of magma and creating a point source of stress underneath the continental lithosphere (Zoback and Thompson, 1978; Geist and Richards, 1993; Glen and Ponce, 2002; Hooper et al., 2007; Camp and Hanan, 2008; Coble and Mahood, 2012). While this model is contested, Hooper et al. (2007) points out that no other model provides a unifying theory for the vast quantities of magma released at the surface during this time period. The Columbia River Flood Basalts cover vast regions of Oregon and Washington while erupting in different phases of magmatism. Locally at the NHSR, the Basalt of Malheur Gorge comprises the flow unit of the Columbia River Flood Basalts. The NNR appears regionally as an arcuate pattern of magnetic anomalies extending from near NHS in a spoke-like pattern southward into Nevada (Glen and Ponce, 2002). These magnetic anomalies arise from dike swarms and graben filling volcanism that comprise the NNR. After the most voluminous eruptions of flood basalts, extension and syntectonic magmatism related to the Oregon-Idaho Graben (OIG) around 15.0 Ma 
created an east to west extension and associated normal faulting in the region around the NHSR (Cummings et al., 2000). The OIG ceased extending 10.5 Ma with the initiation of northwest-southeast trending normal faults associated with the western Snake River Plain (WSRP) that were mostly active between 10.5-9 Ma (Wood and Clemens, 2002). Basin and Range tectonism continues throughout these regional tectonic events. Beginning 17.5 Ma and continuing through the present, Basin and Range extension likely has some role in all of the described tectonic regimes along with current processes around the NHSR (Lawrence, 1976; Dickinson, 2006). Active faulting along the Vale fault Zone (VFZ) is thought to be a reactivation of extinct WSRP faulting, and the affiliated Cottonwood Mountain fault appears within five kilometers of NHS (Knudsen et al., 1994; Cummings et al., 2000; Personius, 2002; Wood and Clemens, 2002). Regional geophysical interpretations suggest that the NHSR lies in an area of anomalously thin crust with high heat flow values (Blackwell, 1978; Eagar et al., 2011). Gravimetric and aeromagnetic anomaly maps outline the boundaries of the OIG and suggest that NHS sits to the southwest of a large basin-bounding fault that is termed the Cottonwood Mountain fault. Local geologic and geochemical surface and borehole studies provide a geologic basis for the local stratigraphy at the NHSR (Edwards and Faulds, 2012; Edwards, 2013).

\subsection{Regional Geology}

NHSG is a structurally controlled geothermal system located in eastern Oregon that lies at the regional intersection of numerous major geologic provinces (Figure 2.1). At the NHSR, granitic basement of the Blue Mountain Olds-Ferry-Izee terrane accreted along the western margin of the North American Craton during the Mesozoic 
(Burchfiel et al., 1992; Cummings et al., 2000; Edwards, 2013). The geologic history of this area is dominated by late Cenezoic activity associated with the emplacement of volcanic rocks from the Columbia River Flood Basalt Group (CRBG), and extension with syntectonic magmatism related to the OIG, WSRP, and Basin and Range taphrogen (Lawrence, 1976; Cummings et al., 2000; Wood and Clemens, 2002; Dickinson, 2010). The results of these tectonic events are a complex array of faulting at and near NHS. This section will describe the major regional geologic and tectonic events since the Miocene, and highlight their relationship with the NHSR.

Roughly $17 \mathrm{Ma}$, the Yellowstone plume head impacted the base of the continental lithosphere beneath the NHSR (Figure 2.2) (Glen and Ponce, 2002; Camp and Ross, 2004; Hooper et al., 2007; Shervais and Hanan, 2008; Coble and Mahood, 2012). After the initial contact with the base of the lithosphere, the plume was forced laterally both north and south from this central location along the pre-accretionary continental margin (Geist and Richards, 1993; Shervais and Hanan, 2008). While the plume head migrated under the lithosphere, it released vast volumes of magma that erupted as the CRBG starting at $\sim 16.8 \mathrm{Ma}$. Interaction of the plume with continental lithosphere caused a delamination of the lithosphere wherein the huge volumes of mafic melt from the plume were contaminated by continental lithosphere (Camp and Hanan, 2008). The delamination of the lithosphere began the period of Miocene to present crustal thinning beneath the NHSR. This model for the genesis of the CRBG has not yet reached scientific consensus, and other models exist that attempt to explain the large volumes of mafic volcanism during this time period. However, Hooper et al. (2007) suggests that no other model provides a unifying theory for the unique patterns of magmatism present in the western United States and is the preferred model used in 
this thesis. For a more complete discussion on CRBG genesis see Hooper et al. (2007); Fouch (2012).

The CRBG rocks began erupting around 16.8 Ma. Over the course of the following two million years, $98 \%$ of the total CRBG, or about 230,000 cubic kilometers of lava erupted over eastern Oregon, Idaho, and Washington (Figure 2.1) (Hooper et al., 2007). The eruption focus started south of NHS near Steens Mountain at 16.6 Ma and progressively moved north along the Chief Joseph dike swarm into southeastern Washington (Hooper et al., 2007). These extensive eruptions covered the study area with a thick package of Malheur Gorge basalt, a member of the CRBG dated by Hooper et al. (2002b) at $16.8 \mathrm{Ma}$ through $15.7 \mathrm{Ma}$.

Coeval with CRBG eruptions, extension along the NNR formed a series of dikes and graben-filling lava flows stretching from Nevada into eastern Oregon near NHS (Figure 2.1) (Zoback et al., 1994). The NNR appears as a series of linear positive magnetic anomalies (Figure 2.2)(Zoback et al., 1994). Glen and Ponce (2002) suggested the NNR formed as the Yellowstone mantle plume created an upward point stress near NHS that when superimposed on mid-Miocene regional stresses produced extension along the radiating spoke-like patterns of the NNR. Rifting associated with the NNR provided another driver for crustal thinning beneath the NHSR.

Subsidence and extension of the OIG began about 15.5 Ma, shortly after the largest volumes of CRBG erupted, and ended at the onset of WSRP tectonism in eastern Oregon at 10.5 Ma (Figure 2.1) (Cummings et al., 2000; Wood and Clemens, 2002). The $100 \mathrm{~km}$ long OIG evolved as a north trending full-graben with syntectonic magmatism and depostition (Cummings et al., 2000). The OIG could be an expression of Miocene Basin and Range extension and crustal thinning in eastern Oregon 


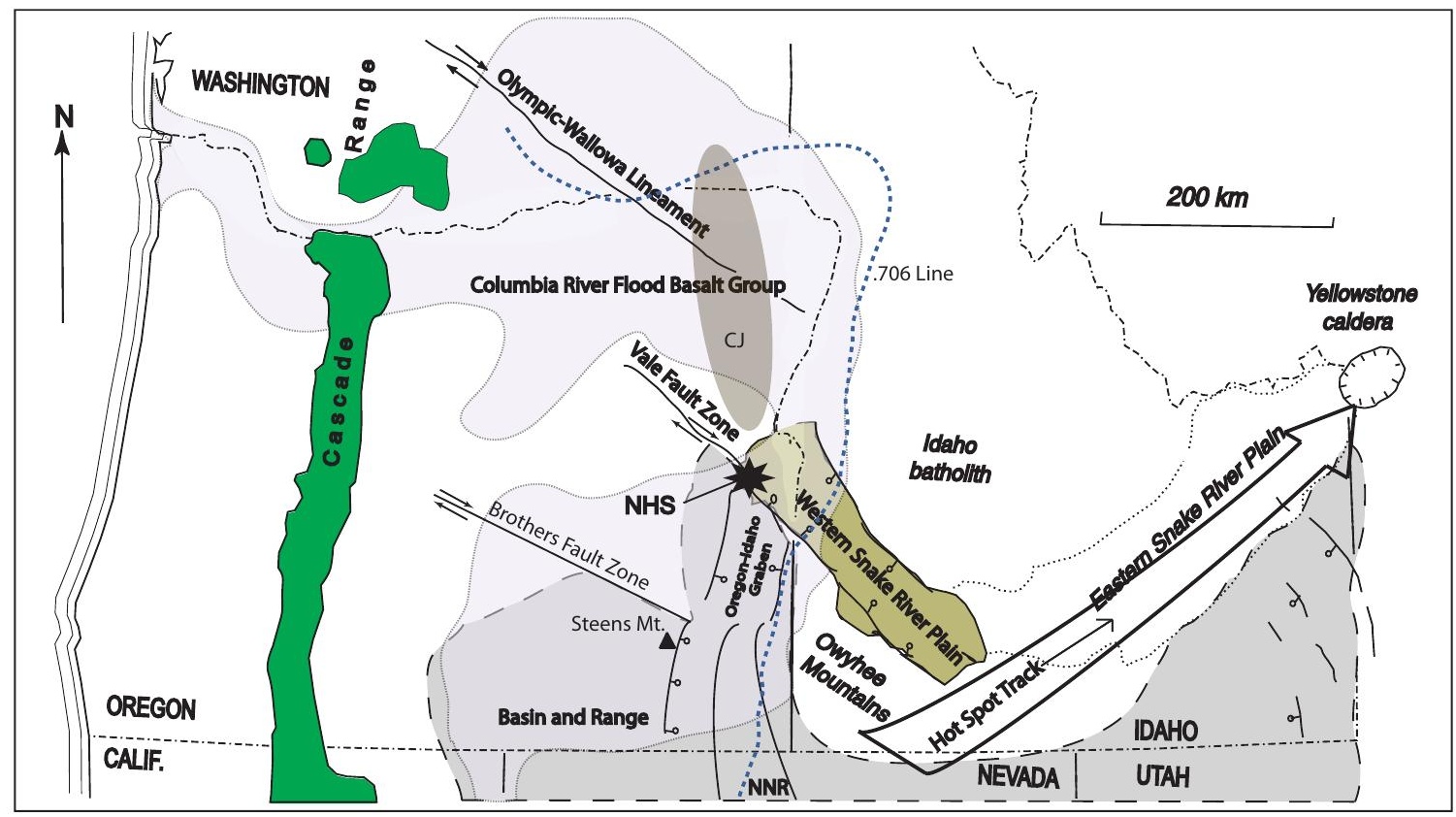

Figure 2.1: Location of NHS geothermal field in eastern Oregon after Cummings et al. (2000). NHS lies at western margin of the stable North American Craton within the intersection and overlap of a number of large tectonic events during the last eighteen million years as shown above. Captions and colors: Northern Nevada Rift- NNR; western Snake river Plain- tan; Columbia River Flood Basalt Group- light grey; Basin and Range-dark grey; Chief Joseph dike swarm (CJ)- brown; Inferred cratonic margin is located at the $S r_{87} / S r_{86} .706$ line which is a blue dashed line. 


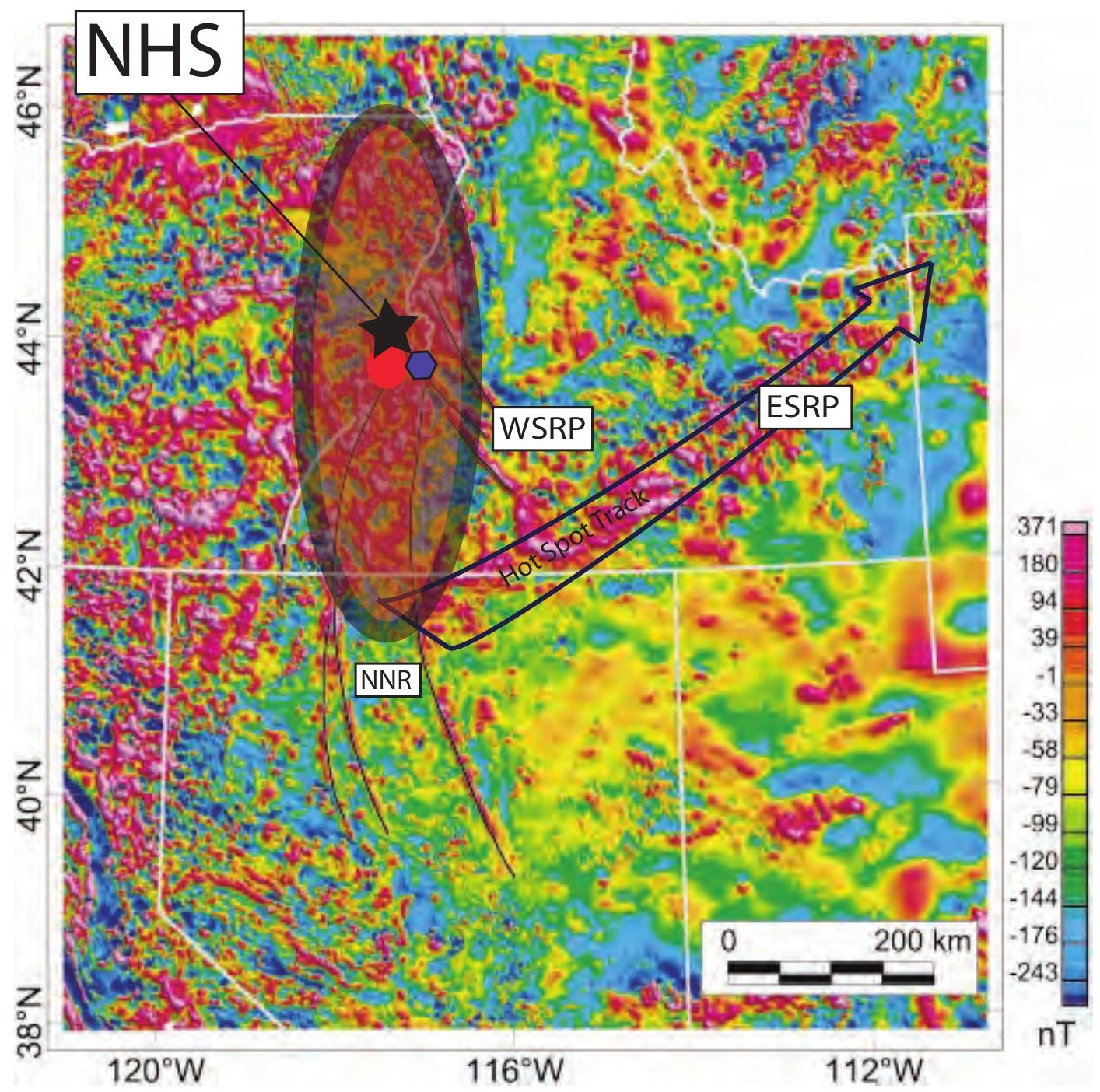

Figure 2.2: Aeromagnetic anomaly map of the intermountain west of the United States after Glen and Ponce (2002). NHS is shown as a black star. The maroon circle is the radius of the Yellowstone mantle plume as it flattens under the continental lithosphere at seventeen million years before present, with its center near NHS (Shervais and Hanan, 2008). The large spoke-like fractures of the Northern Nevada Rift (NNR) appear as magnetic highs, and also suggest a point near NHS may have been the center of the Yellowstone plume (Purple hexagon) (after Glen and Ponce, 2002). 
(Edwards and Faulds, 2012). The NHSR sits at the northern termination of the OIG, where the northerly structural grain of the OIG is dissected by younger northwesterly WSRP faulting along the Vale fault Zone (Hooper et al., 2002a).

Wood and Clemens (2002) defined the WSRP as a 50 to 70 kilometer wide and 300 kilometer long intercontinental rift basin located in southwestern Idaho and eastern Oregon (Figure 2.1). The basin is fault bounded, with vertical offsets of greater than four kilometers, and exhibits both full and half-graben formation along its flanks (Wood and Clemens, 2002; Hooper et al., 2002a). Near the NHSR, the northwest trending Adrian and Vale fault Zones (VFZ) define the western margin of the WSRP, likely forming at 10.5 Ma (Lawrence, 1976; Cummings et al., 2000; Wood and Clemens, 2002; Hooper et al., 2002a). Major extension of the WSRP occurred within an interval of 11.0 to $9.0 \mathrm{Ma}\left(\sim .8 \frac{\mathrm{mm}}{\mathrm{yr}}\right)$, followed by low $\left(\sim .01 \frac{\mathrm{mm}}{\mathrm{yr}}\right)$ late Miocene to recent slip rates (Wood and Clemens, 2002).

The VFZ defines the spatial terminus of the WSRP and is best seen near the NHSR as a suite of northwest trending faults (Figure 2.1) (Hooper et al., 2002a; Ken and Blackwell, 1996). Therefore, the VFZ began as an extensional fault zone which helped define the northern end of the OIG at 10.5 Ma. Lawrence (1976) and Hooper et al. (2002a) note that current movement along the fault zone is dextral with a small offset of less than two to three kilometers. Lawrence (1976) suggests that the VFZ is related to the Brothers fault Zone in that it defines a right lateral step in Basin and Range deformation. Therefore, the VFZ can be considered the northern boundary of the Basin and Range in Oregon. 


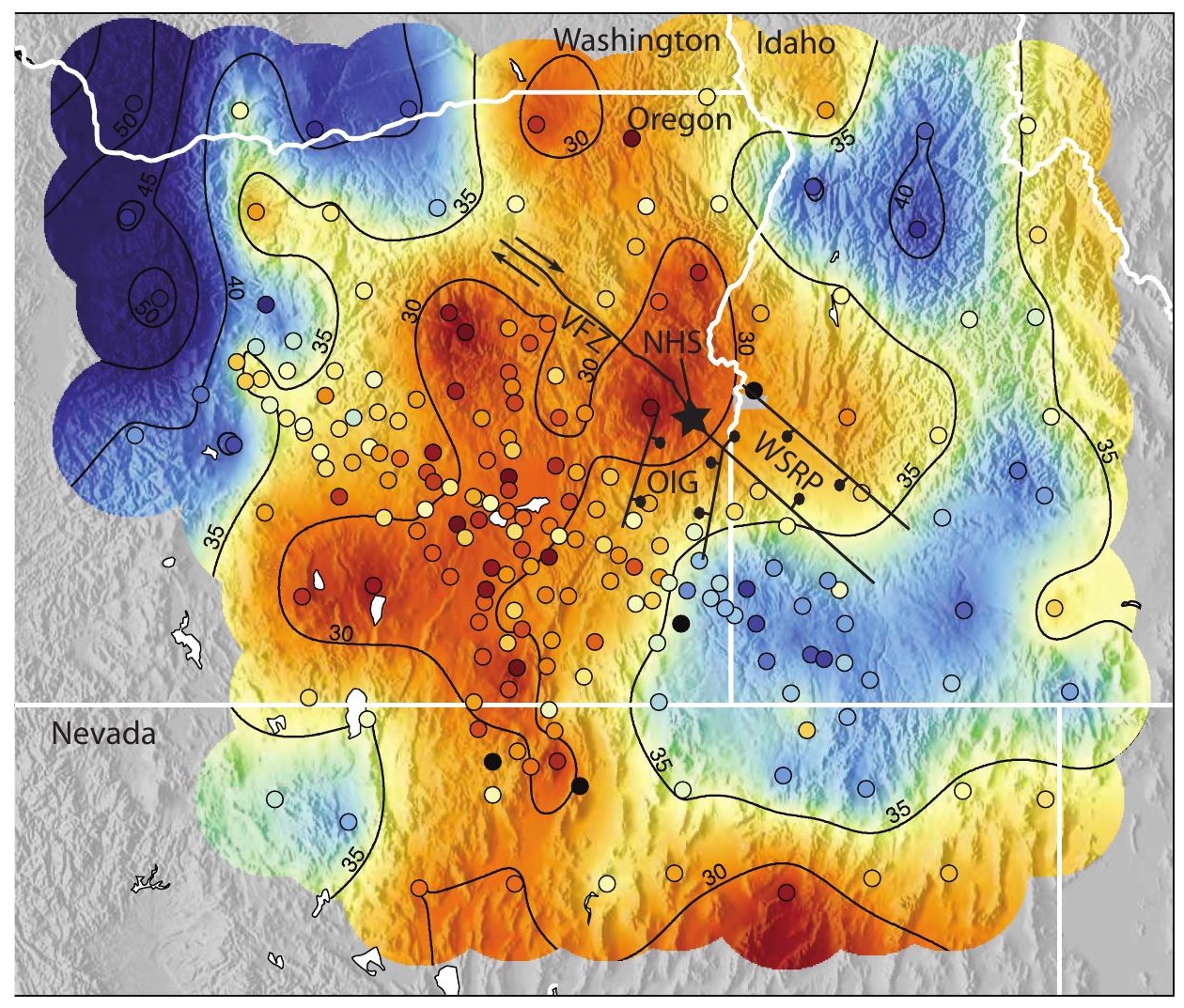

Figure 2.3: Crustal thickness in eastern Oregon from seismic receiver function analysis after Eagar et al. (2011). Note the thin crust of less than thirty kilometers beneath NHS. The thin nature of the crust provides an explanation for the high heat flow values in eastern Oregon and a potential heating mechanism for NHS (Blackwell, 1978). 


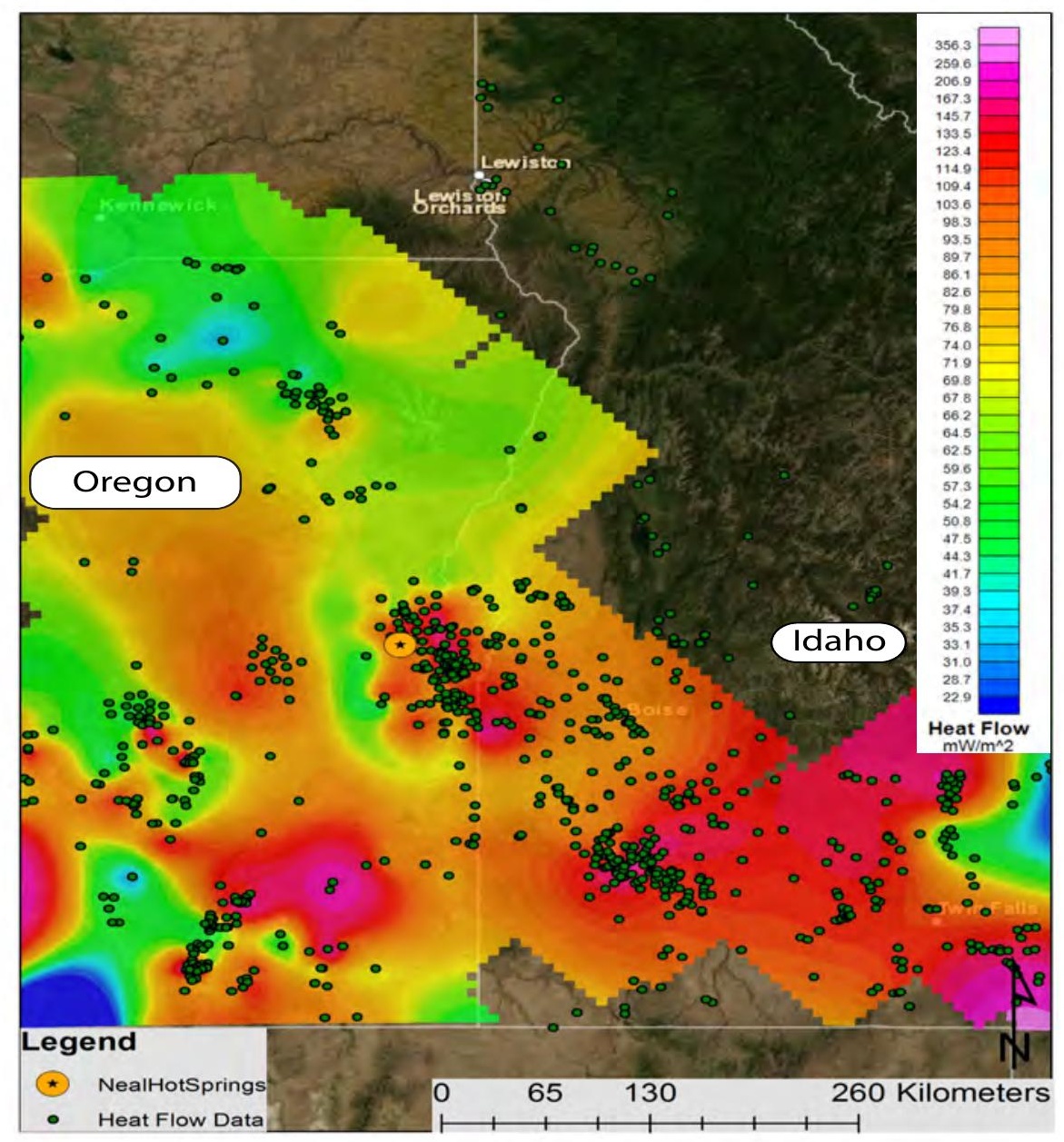

Figure 2.4: Heat flow data from the Southern Methodist University National Heat Flow Database. The crust around NHS (black star within orange circle) exhibits high heat flow values that are more than twice the national average (Wisian et al., 2000). These high heat flows are coincident with a thinned region of crust beneath NHS (Figure 2.3) 


\section{$2.3 \quad$ Regional Geophysics}

Regional geophysical data help constrain crustal thickness, movement of the crust, and heat-flow for the NHSR. Eagar et al. (2011) used seismic receiver function analysis to develop a crustal thickness map of eastern Oregon (Figure 2.3). The NHSR lies above an area of crust less than $28 \mathrm{~km}$ thick, unusually thin compared with the North American average crustal thickness of 36 km (Christensen and Mooney, 1995; Eagar et al., 2011). The anomalously thin crust beneath the NHSR results from the Miocene and later regional extension. Figure 2.4 illustrates regional heat flow data, with heat flow values at NHS more than double the continental average of $60 \frac{\mathrm{mW}}{\mathrm{m}^{2}}$ (Wisian et al., 2000). These high heat flow values are likely related to the thinned continental lithosphere beneath the NHSR, where hot mantle material is closer to the land-surface and extension provides the conduits for vertical heat flow.

Gravity and magnetic data have long been used to investigate density and magnetic susceptibility contrasts in the subsurface (e.g., Blakely, 1995). Regional gravity data reduced with a $2.67 \frac{\mathrm{kg}}{\mathrm{m}^{3}}$ Bouguer slab highlight a rectangular gravity high which follows the border between Idaho and Oregon (Figure 2.5) (Kucks, 1999). This area of high density correlates with the boundaries for the Oregon-Idaho graben described by Cummings et al. (2000), and is likely the expression of volcanism associated with extension and related subsidence. Figure 2.6 depicts the regional magnetic anomaly map of eastern Oregon. The maxima of the horizontal gradients (HGM) of the magnetic field indicate possible subsurface magnetic susceptibility contacts such as a fault (e.g., Blakely, 1995; Phillips, 1997b). By tracing the HGM northeast of NHS, I identify a large basin that is bounded by a fault that aligns with the VFZ from Lawrence (1976). This magnetic lineament is located within three kilometers of NHS and has 
been identified as the Cottonwood Mountain fault(Knudsen et al., 1994; Personius, 2002). The fault is classified as active and exhibits down-to-the-northeast normal fault motion with a strike of north-northwest (Knudsen et al., 1994).

Geodetic and paleomagnetic measurements of the northwestern United States indicate post Neogene clockwise rotation of the Pacific Northwest relative to stable North America (Figure 2.7) (McCaffrey et al., 2007; Payne et al., 2012). McCaffrey et al. (2007) suggested the dextral motion along the Olympic-Wallowa Lineament denotes the boundary between Oregon and the paleo-North American craton and accommodates regional strain. McCaffrey et al. (2007) interpreted the clockwise movement seen in the Pacific Northwest as being driven by shear in the Walker Lane Belt of the Basin and Range taphrogen. Payne et al. (2012) related a sharp decrease in westward velocities at the western boundary of the WSRP to indicate an area of compression north of the NHSR. Overall, motion around the NHSR is directed to the northwest relative to stable North America, but local geodetic measurements cannot be resolved from these data.

\subsection{Local Geology at Neal Hot Springs}

The NHSG was developed by U.S. Geothermal Inc. nearly thirty years after its original exploration by Chevron as a commercial resource in the late 1970s (Niewendorp, 2011). The field is located $0.5 \mathrm{~km}$ west of NHS, where $90^{\circ} \mathrm{C}$ water flows to the surface (Figure 2.8). The 23 megawatt power plant extracts water at temperatures greater than $138^{\circ} \mathrm{C}$ along the Neal fault between the depths of 680 and 1935 meters. Within the NHSG, the Neal fault strikes north-northwest and dips $60^{\circ}$ southwest.

Geologic and geochemical studies within the NHSR helped Edwards (2013) de- 


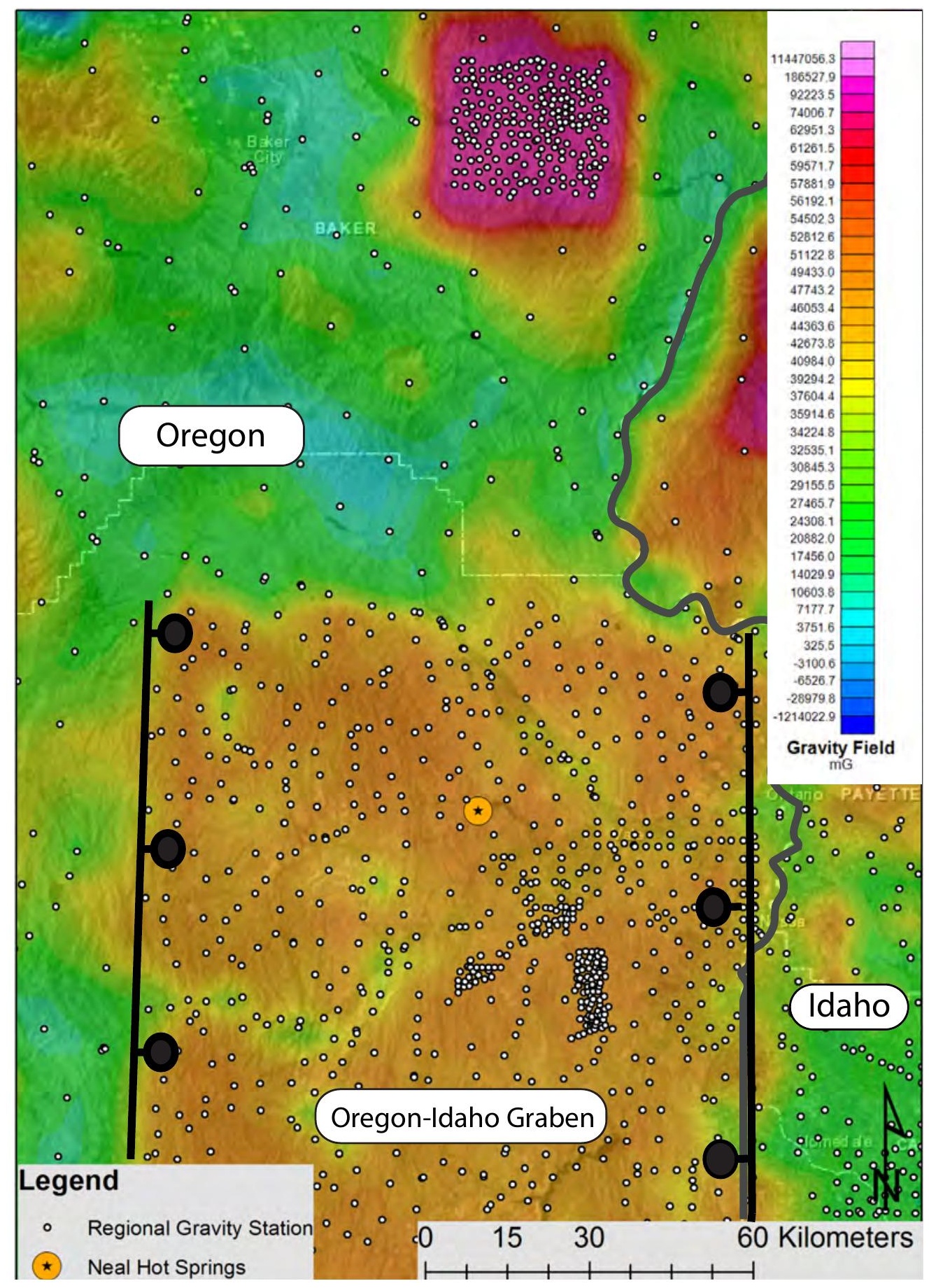

Figure 2.5: Regional gravity data and gravity stations of eastern Oregon and western Idaho (Kucks, 1999). The large gravity high outlined by normal faults above likely represents the extent of graben filling volcanism associated with the Oregon-Idaho Graben. 


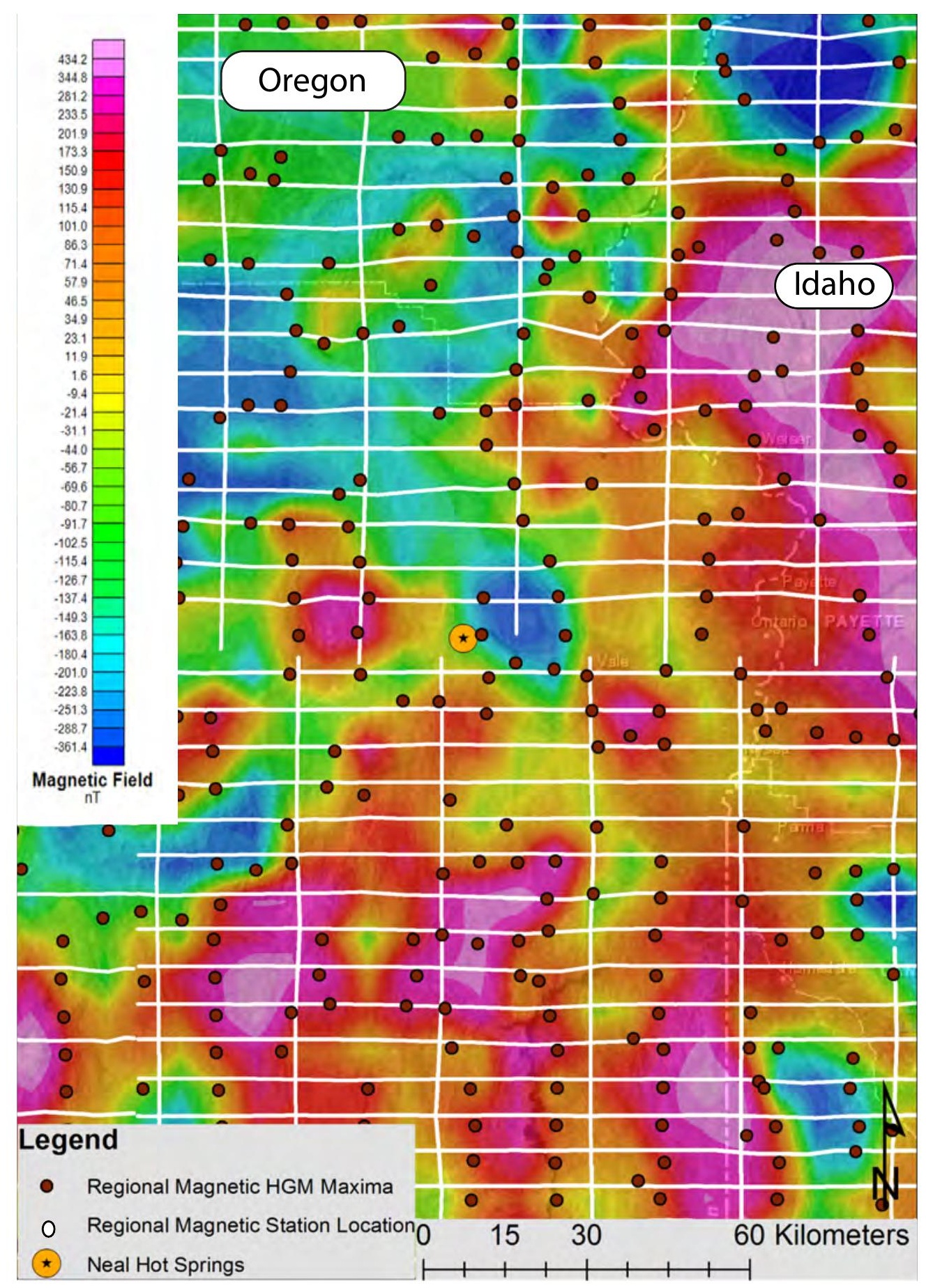

Figure 2.6: Regional magnetic data eastern Oregon and western Idaho (Bankey et al., 2002). The maxima of the horizontal gradients (HGM) are plotted as maroon dots. These locations indicate subsurface magnetic contacts (Phillips, 1997b). By following the trend of the HGM a fault is interpreted northeast of NHS which follows the trend of the Vale fault Zone and bounds a large basin (Lawrence, 1976). This is likely an expression of the Cottonwood Mountain fault (Personius, 2002). 


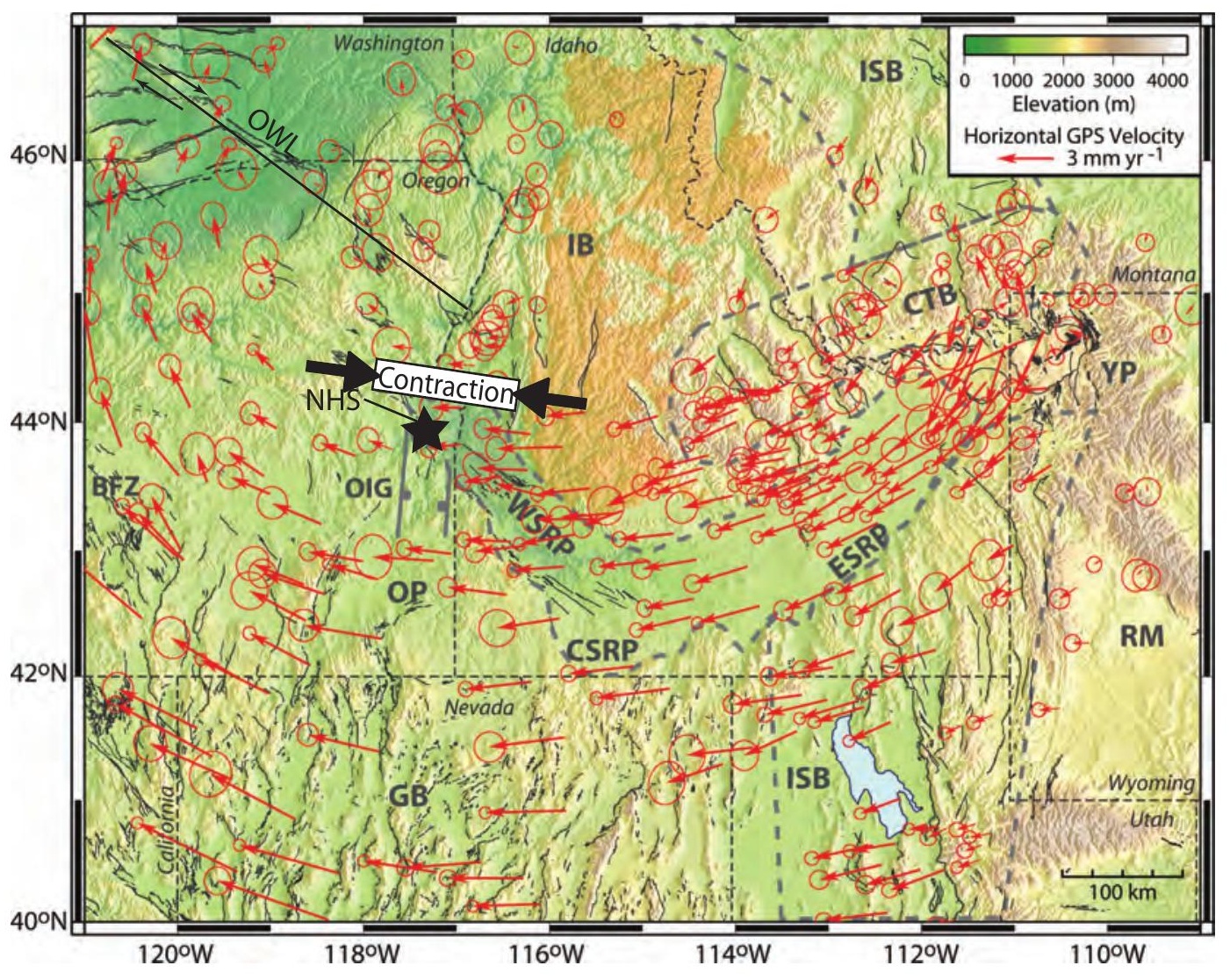

Figure 2.7: GPS geodetic data in eastern Oregon and Idaho after Payne et al. (2012). Clockwise rotation of the Pacific Northwest relative to stable North America is accommodated along the Olympic Wallowa Lineament (OWL) (McCaffrey et al., 2007). Payne et al. (2012) suggest that a rapid decrease in velocity at the western margin of the western Snake River Plain leads to an area of compression north NHS. For an explanation of the other labels please see Payne et al. (2012). 
velop a local structural and stratigraphic framework. Original geologic mapping in the area was unpublished, but provided an initial framework for geophysical survey design during a DOE funded, Boise State University led geophysics field camp in May, 2011. More recent geologic mapping by Edwards (2013) focused on the NHSR and was utilized during this research (Figure 2.9). Edwards (2013) mapped a number of faults, and described the structural framework of the western portion of the NHSR as gently, generally east-dipping fault blocks cut by north-northwest striking normal faults. Major mapped faults by Edwards (2013) within the NHSR are shown in Figure 2.10. The most prominent topographic landmark at NHS is a north-striking horst block that is bound on the west by the Neal fault and the east by the Hope Butte fault. Fluid movement at the NHSG is controlled by high-permeability along the Neal fault, as all geothermal production occurs along this fault at depth. The surface springs are found where the fault intersects the surface (Edwards, 2013).

The localized stratigraphy at the NHSR is shown in Figure 2.11 (Edwards and Faulds, 2012). Basement granitic rocks have been dated as Jurassic in age (Carl Hoiland, Stanford University, personal comm.). These rocks are associated with the accreted Olds-Ferry-Izee terrane (Edwards, 2013). Sitting nonconformably above the granite is the thick middle-Miocene Basalt of Malheur Gorge (Tbm) (Edwards, 2013). Conformably overlying the Basalt of Malheur Gorge is the Hog Creek Sequence, these early OIG rocks consist of contemporaneous eruptions of the Cottonwood Mountain Rhyolite (Trc) and Hunter Creek Basalt (Th), which are intercalated with volcaniclastic rocks likely sourced from these same units (Edwards, 2013). Conformably overlying the Hog Creek Sequence, OIG-filling rocks include an intrusive diabase basalt (Tdb), lacustrine Drip Springs Formation (Tds), and the Vines Hill Andesite 
(Tva) (Edwards, 2013). Conformably overlying the OIG rocks, WSRP formations contain late-Miocene volcaniclastic and lacustrine poorly lithified Bully Creek Formation (Tbc), Sourdough olivine basalt, and lacustrine and fluvial Idaho Group rocks (Tid) (Edwards, 2013). Intercalated with the Idaho Group, the Neal Basalt (Tbn) is shown within this thesis to have a vent near NHS. Dacite-scoria (Tds) caps the section at the NHSR, with small vent features located within the area (Edwards, 2013). 


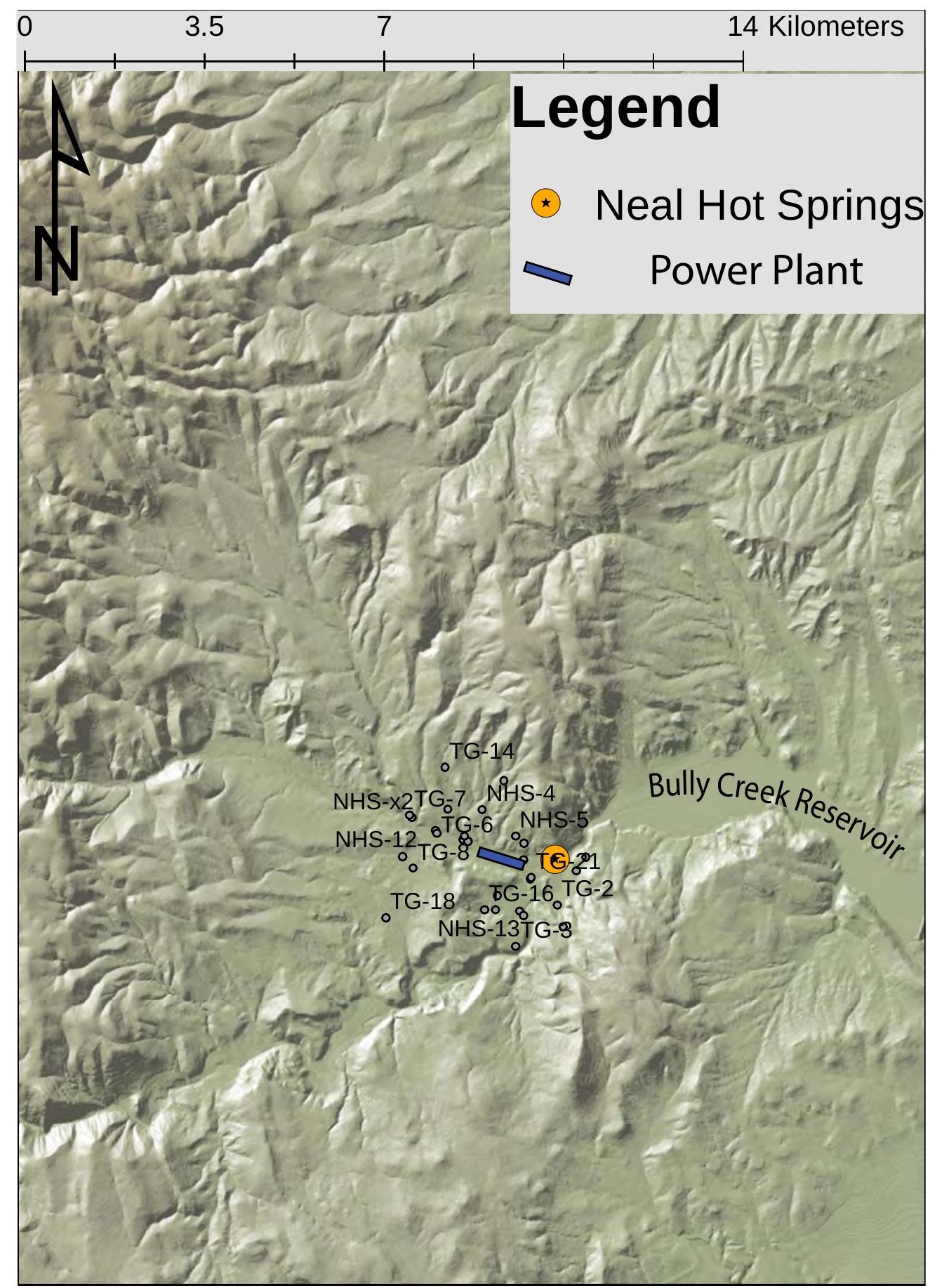

Figure 2.8: Digital elevation model of NHS showing the location of boreholes and the geothermal power plant (Image taken from GeoMapApp) (Ryan et al., 2009). 


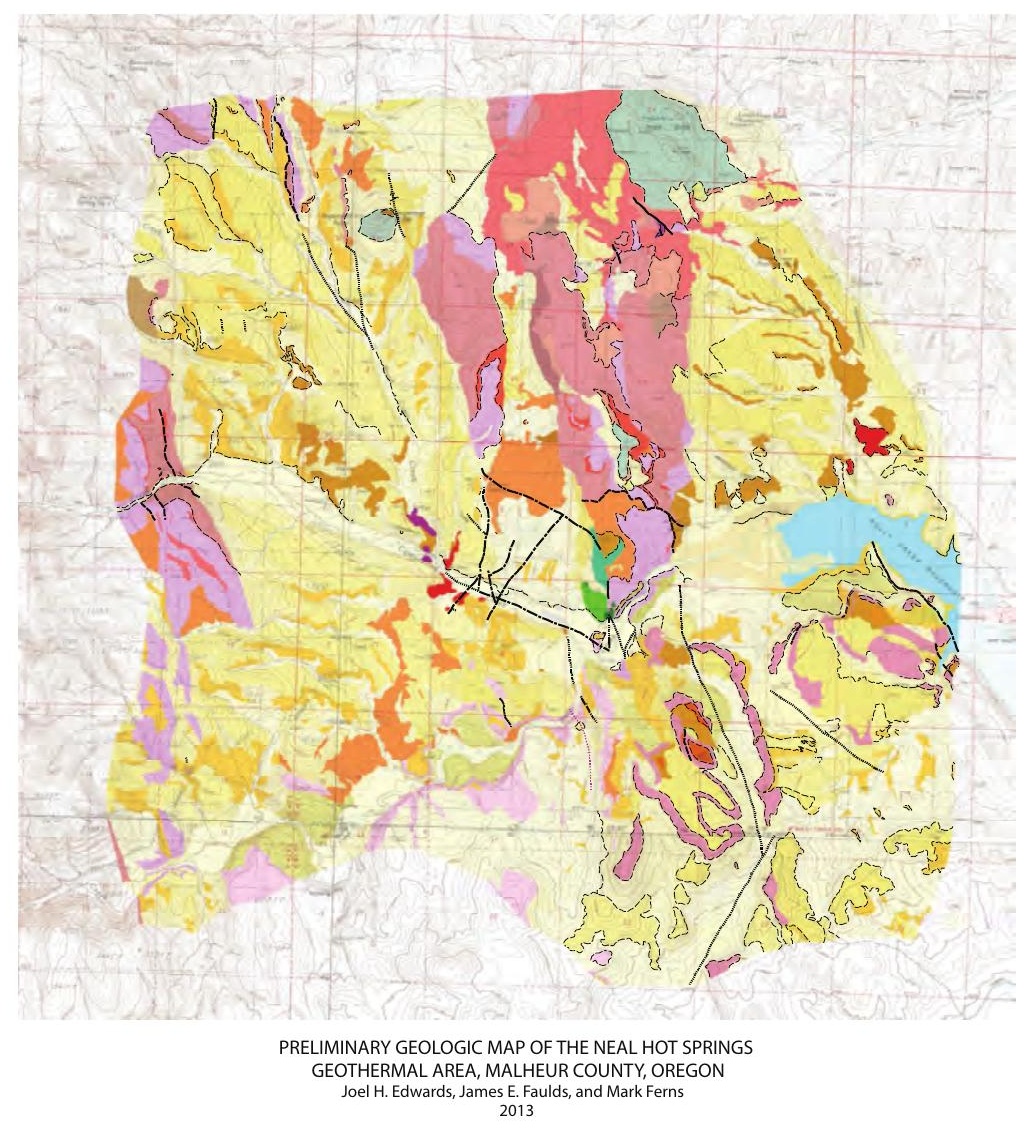

Figure 2.9: Geologic map of the NHS geothermal area with the black star representing NHS (Edwards, 2013). 


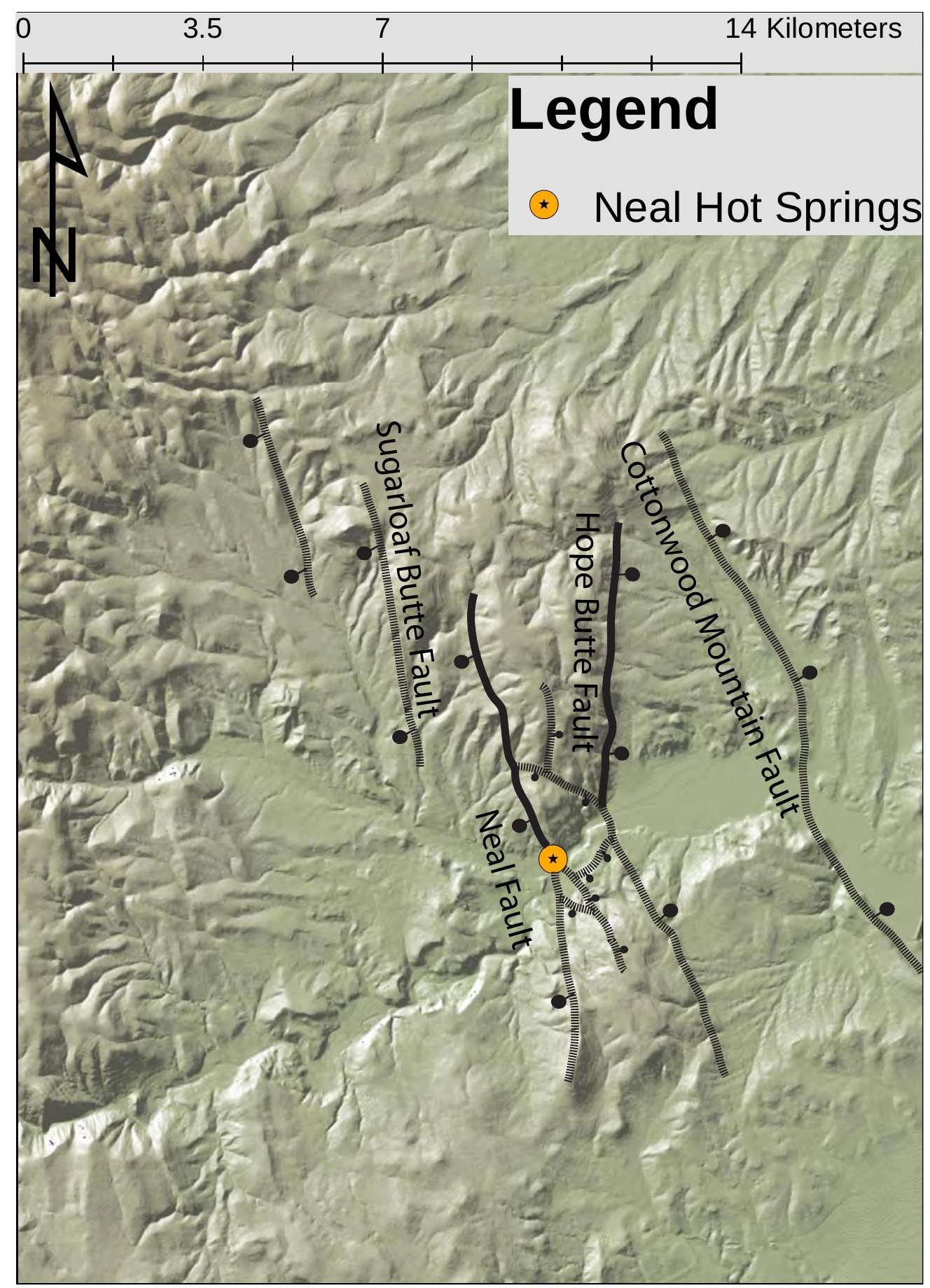

Figure 2.10: Map of NHS highlighting major structures immediately surrounding NHS mapped by Edwards (2013). Balls indicate a normal fault, with the ball on the hanging wall. The dashed lines are the location of inferred faults. 


\begin{tabular}{|c|c|c|c|c|c|}
\hline Age & Se ence & Unit $\mathrm{Na}$ e & Thick ess & Rock Typ & Red scoraceous plag \\
\hline 2 & Kivett & Dacite Scoria & $5-12 m$ & & Ioclase and sanidine \\
\hline$\stackrel{\tilde{e}}{u}$ & & Id $h \quad G$ & & 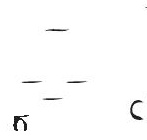 & $\begin{array}{l}\text { - Silicifi d gastro } \\
\text { po rich limeston } \\
\text { hienly interlay d }\end{array}$ \\
\hline
\end{tabular}

Neal Basalt

Sourdough Basalt

Figure 2.11: Stratigraphy at NHS from Edwards and Faulds (2012). Note that the Jurassic basement granite of the Olds-Ferry-Izee Terrane is not shown. 
different mass can be juxtaposed is when crossing a tectonic fault where a vertical or lateral offset of geologic layers may be present. In addition to tectonic processes that may juxtapose rocks of varying densities, large density contrasts within the NHSR exist between volcanic and poorly consolidated sedimentary rocks (Figure 2.9). Where faults or changing lithologic conditions have placed distinct density units next to each other, measurable variances in the gravity field may be observed.

Field-based gravity measurements cannot be used directly to investigate near surface density distributions due to the minute near surface density distribution with respect to whole earth densities. On average, the value for the acceleration due to gravity at the earth's surface is 980 Gals (e.g., Telford et al., 1990). At the NHSR, anomalies of interest were less than 15 milliGals, or less than $.00015 \%$ of the average total field. Modern gravimeters are able to resolve these minute fluctuations in gravity, and are accurate to within .01 milliGals (e.g., Long and Kaufmann, 2013). To investigate the shallow subsurface, a series of corrections must be applied to the total gravity field data in order to isolate near surface gravity effects. In practice this process is called reducing the gravity field to a Complete Bouguer Anomaly, and can be shown as (e.g., Blakely, 1995):

$$
\Delta g_{c b a}=g_{o b s}-g_{f a}-g_{s b}-g_{t}-g_{o}
$$

where $g_{c b a}$ is the Complete Bouguer Anomaly, $g_{o b s}$ is the total observed gravity field, $g_{f a}$ is the free-air correction, $g_{s b}$ is the Simple Bouguer Anomaly, $g_{t}$ is the terrain correction, and $g_{o}$ is the theoretical gravity, or gravity of the ellipsoid.

Gravity data at the NHSR were acquired by U.S. Geothermal Inc. in 2006. A total of 562 stations were recorded in a grid, with roughly a 300 meter station spacing. I 
received the data with no tie to absolute gravity in the area, so the data had a constant shift in the measured field relative to absolute gravity. With help from Jonathan Glen of the United States Geological Survey, the gravity data were tied to absolute gravity at a nearby benchmark where absolute gravity was known. This process involved reoccupying prior base station sites of the original survey, measuring the field, and measuring the gravity field at a nearby benchmark where absolute gravity was known. From these measurements, we calculated and applied the datum shift between readings taken from the gravimeter and the absolute value of gravity in the area to our field measurements. After the static corrections applied to the field data, I reduced the data to a Complete Bouguer Anomaly value with a Bouguer Slab derived from Nettleton's Method of $2.2 \frac{\mathrm{kg}}{\mathrm{m}^{3}}$ (Figure 3.2) (e.g., Telford et al., 1990).

The amplitude and wavelength of gravity anomalies are fundamentally controlled by the shape and depth of the causative body in the subsurface (e.g., Blakely, 1995). When a source is close to the surface, the resulting anomaly has a large amplitude and short wavelength relative to that same source at a deeper location. When processing the gravity data, I focused on highlighting wavelengths longer than 500 meters that are more likely to arise from kilometer scale sources, such as structural offsets, rather than sub-hundered meter scale sampling noise or near surface local density variations. I bandpass filtered the data using a technique developed by Phillips (1997a, 2007) that is based on work by Syberg (1972). Matched bandpass filtering is a spatial Fourier Transform based technique that involves an analysis of the logarithm of the radially averaged power spectrum and wavenumber of the gravity data (Figure 3.2). I then designed a number of bandpass filters from the linear portions of the spectrum that effectively segregate the higher frequency shallow anomalies from lower frequency 

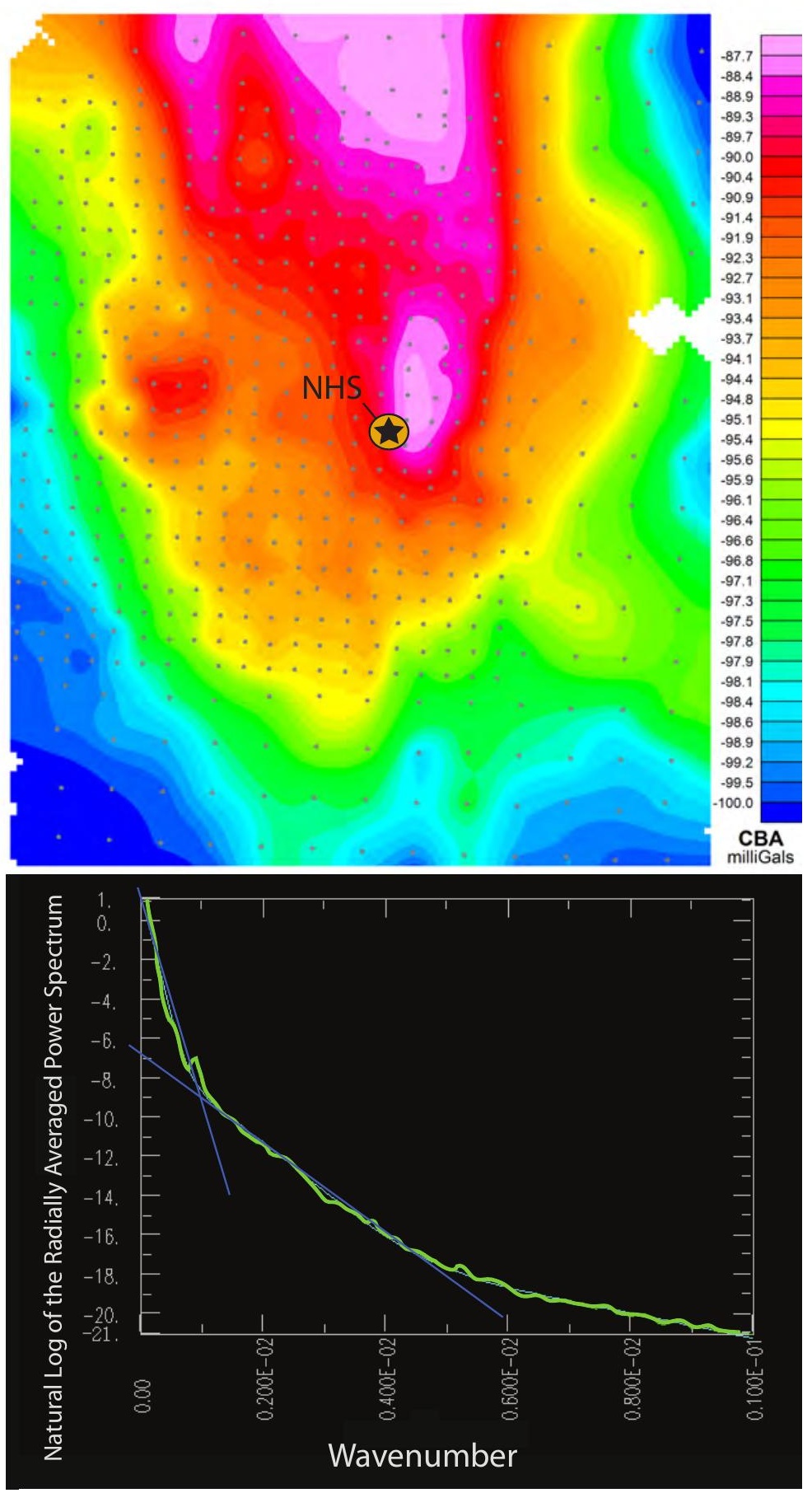

Figure 3.2: The Complete Bouguer Anomaly map of NHS. Note the small variations in the field and slightly pockmarked appearance. These features were removed with matched filtering. The bottom graph depicts the radially averaged power spectrum versus wavenumber, and my linear fits to the spectrum for matched filtering as blue lines. 

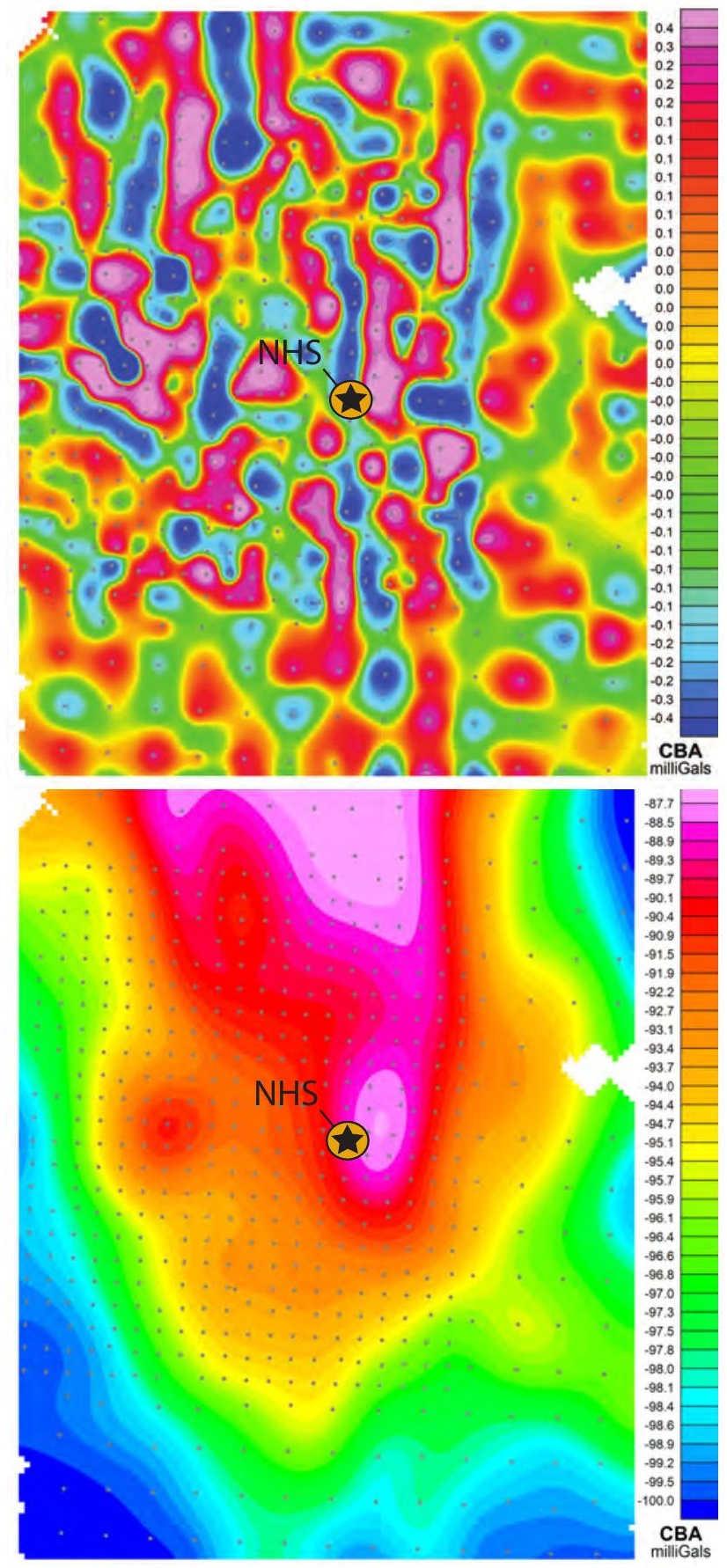

Figure 3.3: Top image shows the short wavelength, high frequency content after filtering, while the bottom is the longer wavelength. Note the small range (.8 milliGal) of the short wavelength content, and the correlation between gravity stations and noise. Subsequent processing and interpretation is made on the longer wavelength content with the noise removed. 
deeper anomalies (Nabighian et al., 2005). The results from the filters shown in Figure 3.2 are illustrated in Figure 3.3.

To isolate subsurface density contacts, the maxima from both the Horizontal Gradient Method (HGM) and Analytic Signal (AS) were employed on the filtered gravity data at the NHSR (Figure 3.4) (Blakely and Simpson, 1986; Roest et al., 1992). Both methods rely on derivatives of the field, and therefore are particularly sensitive to the high frequency (near surface) content in the data. In this case, high-frequency noise was removed via matched filtering. If $G(x, y)$ is the measured vertical component of the gravity field, then the horizontal gradient magnitude, $H G(x, y)$ is given by (Blakely, 1995)

$$
H G(x, y)=\sqrt{\left(\frac{d G}{d x}\right)^{2}+\left(\frac{d G}{d y}\right)^{2}}
$$

Blakely and Simpson (1986) indicate that vertical gravity contacts are located beneath the maximum of the horizontal gradient of the gravity field, and Grauch and Cordell (1987) demonstrate that when a density contact is dipping, such as at a fault, the maxima of the horizontal gradients are deflected down-dip. The HGM for the filtered gravity data were found using Phillips (1997a, 2007) algorithms which uses a grid searching approach to locate local maxima within the gridded data. The HGM are shown as blue dots in Figure 3.4. The $A S(x, y)$ can be given by (Roest et al., 1992)

$$
A S(x, y)=\sqrt{\left(\frac{d G}{d x}\right)^{2}+\left(\frac{d G}{d y}\right)^{2}+\left(\frac{d G}{d z}\right)^{2}}
$$

and is also known as the total gradient method (Nabighian et al., 2005). The 
AS generally provides good subsurface density contacts independent of dip (Phillips, 1997b). Using Phillips (1997a, 2007) algorithms, the AS for the filtered gravity data were found and are shown in Figure 3.4 as maroon dots.

The Complete Bouguer Anomaly map indicates a region of higher density immediately east of NHS that is flanked by lower density on all sides (Figure 3.2). Both the HGM and AS show linear and continuous along strike density contrasts that I interpret as faults that place high-density volcanic units next to low-density sedimentary units (Figure 3.4). I label the faults according to the names given by the Edwards (2013) geologic map. Exceptions to the Edwards and Faulds (2012) nomenclature are the Coyote fault and Cottonwood Creek fault; neither were not mapped at the surface. By overlaying the HGM and AS, I interpret dip directions on some of the faults due to the down-dip displacement of the HGM. The HGM indicate a sudden eastward deflection of the Neal fault with an arcuate return to the west. This is an interesting result of the HGM, and is supported by neither the AS nor any surface topography that would indicate a major, west dipping structure in this location. A circular anomaly highlighted with a blue circle in Figure 3.4 located in the western portion of the gravity survey is hard to interpret without any further data, but due to the continuity of the HGM and AS is likely a high-density geologic feature and not an artifact within the data.

Gravity data were further utilized to test subsurface geometry and structural models along two transects, A-A' and B-B' through forward modeling and inversion (Figure 3.1). Modeling performed with the Geosoft GM-SYS software helped integrate interpretations from gravity, magnetic, seismic, and electromagnetic methods. These detailed interpretations will be presented in Chapter 4 . 
In summary, I utilized gravity data acquired at the NHSR to infer the density distribution within the upper few kilometers of the subsurface. I locate the Neal fault, Hope Butte fault, and Sugar Loaf Butte fault and define the dip direction on each. The two previously unknown southerly dipping Coyote and Cottonwood Creek faults were identified beneath a layer of sedimentary fill and a dense circular anomaly within the western part of the survey was identified.

\subsubsection{Magnetic Methods}

The magnetic method relies on the measurement of the earth's magnetic field at varying positions along the surface of the earth (e.g., Telford et al., 1990). Similar to the gravity method, lateral variations in the magnetic field arise from a contrasting subsurface rock property- the magnetic susceptibility $(\kappa)$. For small inducing magnetic fields such as the 50,000 nanoTesla field of earth, the $\kappa$ of subsurface rocks is related to the magnitude of induced magnetic fields of subsurface bodies through the following formula (e.g., Blakely, 1995):

$$
\mathbf{M}=\kappa \mathbf{H}
$$

where $H$ is the magnetic field intensity, and $M$ is the magnetization. When $\kappa$ contrasts occur in the subsurface, magnetic anomalies are produced due to the unique induced fields on either side of the contact. $\kappa$ contrasts can arise from geologic structure, edges of rock units, or some form of magnetic mineral alteration. The induced magnetization in subsurface rocks interferes with the magnetic field of the earth either constructively or destructively, which is measured by magnetometers as the total magnetic intensity (TMI) at the surface. At the NHSR, large contrasts in $\kappa$ 


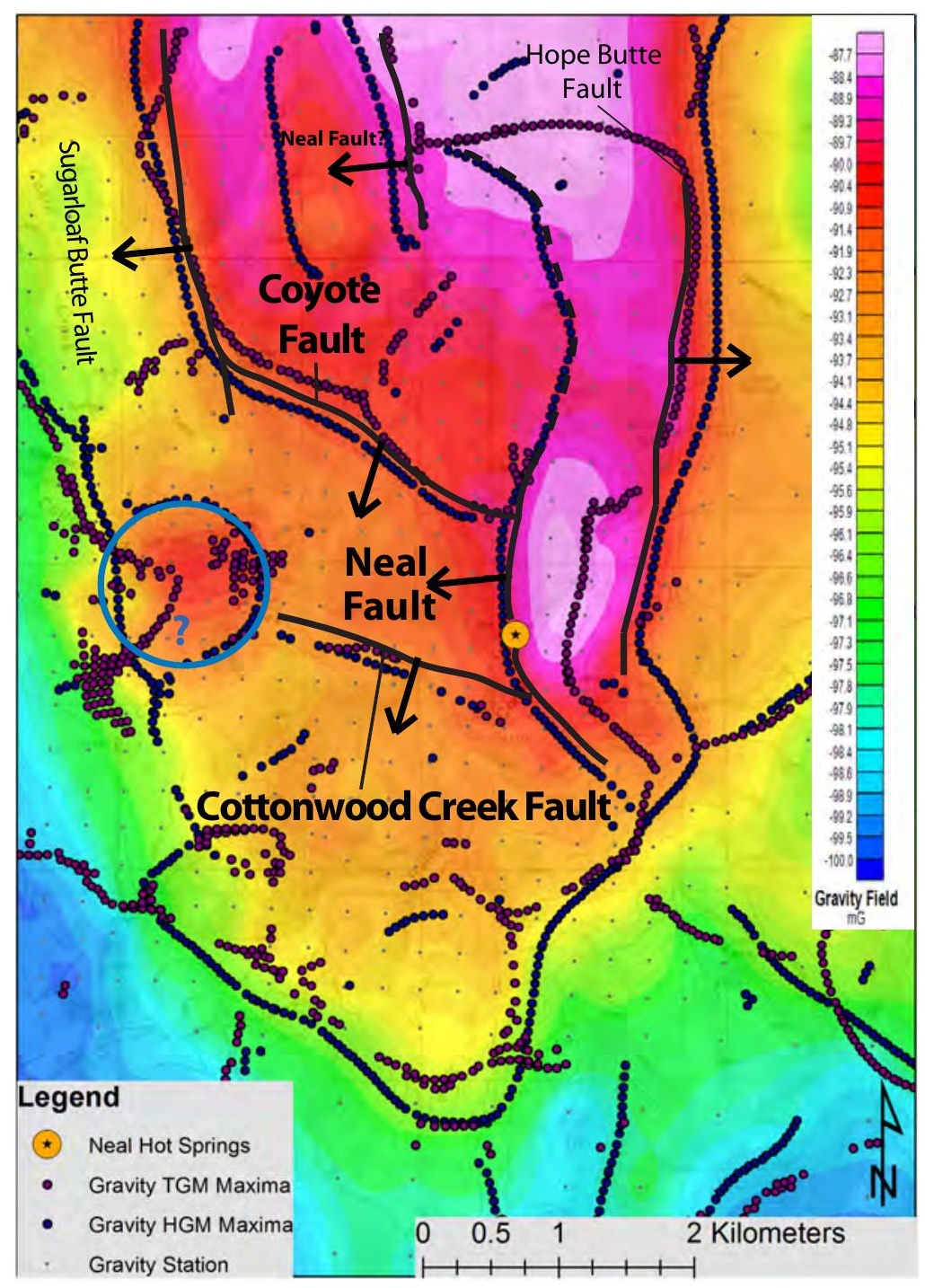

Figure 3.4: Filtered gravity overlain on a topographic map of NHS. Gravity stations are shown as grey dots. The maxima of the Horizontal Gradient Method (Blue dots), and maxima of the Analytic Signal (Maroon dots) are shown (Blakely and Simpson, 1986; Roest et al., 1992). These suggest subsurface density contacts and are interpreted as faults. Dip directions for interpreted faults are also shown by arrows and were interpreted from overlaying the maxima of the Analytic Signal and Horizontal Gradient Method (Phillips, 1997b). The sudden eastward change in strike of the Neal fault is questionable, as no AS locations nor topography suggest a westerly dipping structure. Therefore this feature is highlighted with a dashed line. The circular feature to the west shows a continuous HGM and could likely be geologic. 
occur between volcanic and sedimentary rocks/air interfaces that produce variations in the TMI of up to $500 \mathrm{nT}$. I interpret many of these anomalies as either tectonic faults or geothermal alteration of host rocks (Figure 3.5).

Ground magnetic data within the NHSR were acquired during the period from January 2012 through July 2012. Two magnetometers were used to collect the data, a roving Geometrics G-858 Caesium-vapor magnetometer and a base-station Geometrics G-856 proton-precession magnetometer. The base station made recordings every one minute to monitor the diurnal variation in the inducing earth magnetic field for corrections to the roving data. We recorded data with the rover every three seconds along a series of profiles and small grids (Figure 3.5 and Figure 3.6). Corrections to the roving data included the removal of any diurnal variation, then the addition of a median field extracted from all the collected data back onto each reading to account for temporal variations in the earth field during the months between some of these surveys.

I analyzed two magnetic surveys for my study. The first survey is referred to as the NHSR survey and was designed to investigate magnetic anomalies at the NHSR in a series of long magnetic profiles (Figure 3.5). The second survey is referred to as the hot spring survey and focused directly on NHS (Figure 3.6). The hot spring survey consists of a tightly spaced measurement grid aimed at exploring magnetic mineral alteration from the surface springs (Figure 3.6). Both datasets were gridded with a Minimum-curvature algorithm (Briggs, 1974). The NHSR survey was gridded with a grid cell size of 50 meters. A line spacing of roughly one kilometer did not provide adequate data coverage to resolve detailed magnetic variations within the NHSR. Therefore, my interpretations were only considered valid within 100 meters of 
each surface profile. In an effort to reduce short-wavelength near surface features and enhance longer-wavelength anomalies, the data were upward-continued 200 meters (e.g., Blakely, 1995). Upward-continuation of magnetic data recalculates the observed field as it would be measured at an elevation greater than the actual measurement elevation. This effectively smooths the dataset and suppresses short-wavelength noise. The smaller hot springs survey was gridded with a grid cell size of 10 meters. I performed no filtering on the smaller dataset.

Similar to the gravity method, maximum gradients in the magnetic field are located over subsurface magnetic susceptibility contrasts (Blakely, 1995). Therefore, to investigate the NHSR for tectonic faults that may act as conduits for fluid flow, steep gradients in the magnetic field were identified in the NHSR data and are shown in Figure 3.5. To the east, a gradient that continues through two magnetic profiles could represent the Cottonwood Mountain fault (Knudsen et al., 1994). The same steep gradient is not expressed in the southern magnetic profile, and instead a magnetic low appears along strike of the mapped fault. This magnetic low is likely due to an exposed dacite-scoria unit having a reversed remnant magnetization that distorts any signal from the Cottonwood Mountain fault in this location. The dacite-scoria is approximately $2 \mathrm{Ma}$, which falls within a geomagnetic reversal defined by Fowler and Holloway (2006). A strong gradient that trends from high magnetic intensity to low intensity is aligned north to south and I interpret this lineament as the Hope Butte fault (Edwards, 2013). The Neal fault is represented by a steep gradient in the magnetic field that strikes slightly west of north. The lineament continues both north and south of the NHS. A small fault intersects the Neal fault orthogonally just north of the surface springs, and likely dips to the south. Additionally, the Sugar 
Loaf Butte fault is recognized on two magnetic profiles, and an unidentified feature in the southwest of Figure 3.5 could be a down-to-the-northeast, northwest-trending blind fault.

The hot springs survey shown in Figure 3.6 covers a small region directly over the surface springs. A magnetic high coincident with the surface springs is an oddity in that magnetic studies conducted at other geothermal fields exhibit a magnetic low over the geothermal site from geothermal water degradation of magnetic minerals (Cumming, 2009; Hunt et al., 2009). The magnetic high at NHS could be the result of geochemical conditions within the springs that are favorable for preserving or precipitating magnetic minerals (Jonathan Glen, USGS, personal comm.).

In summary, I used magnetic data acquired at the NHSR to infer the $\kappa$ distribution within the upper few kilometers of the subsurface. I locate the Neal fault, Cottonwood Mountain fault, Hope Butte fault, and Sugar Loaf Butte fault where they cross magnetic profiles, and correlate similar anomaly shapes to define the faults across numerous profiles. A possible fault to the southwest of the NHSR was interpreted to dip to the northeast. Magnetic surveys provide a way to map shallow geothermal waters indirectly at NHS by identifying the geothermal alteration caused by the surface springs as a magnetic high.

\subsection{Seismic Methods}

Reflection seismic methods rely on elastic waves that propagate through the subsurface and reflect off or refract along boundaries of varying density or seismic velocity (e.g., Parasnis, 1996). Recording the timing from source to receiver of returned seismic energy and applying necessary processing steps allows an interpreter to make 


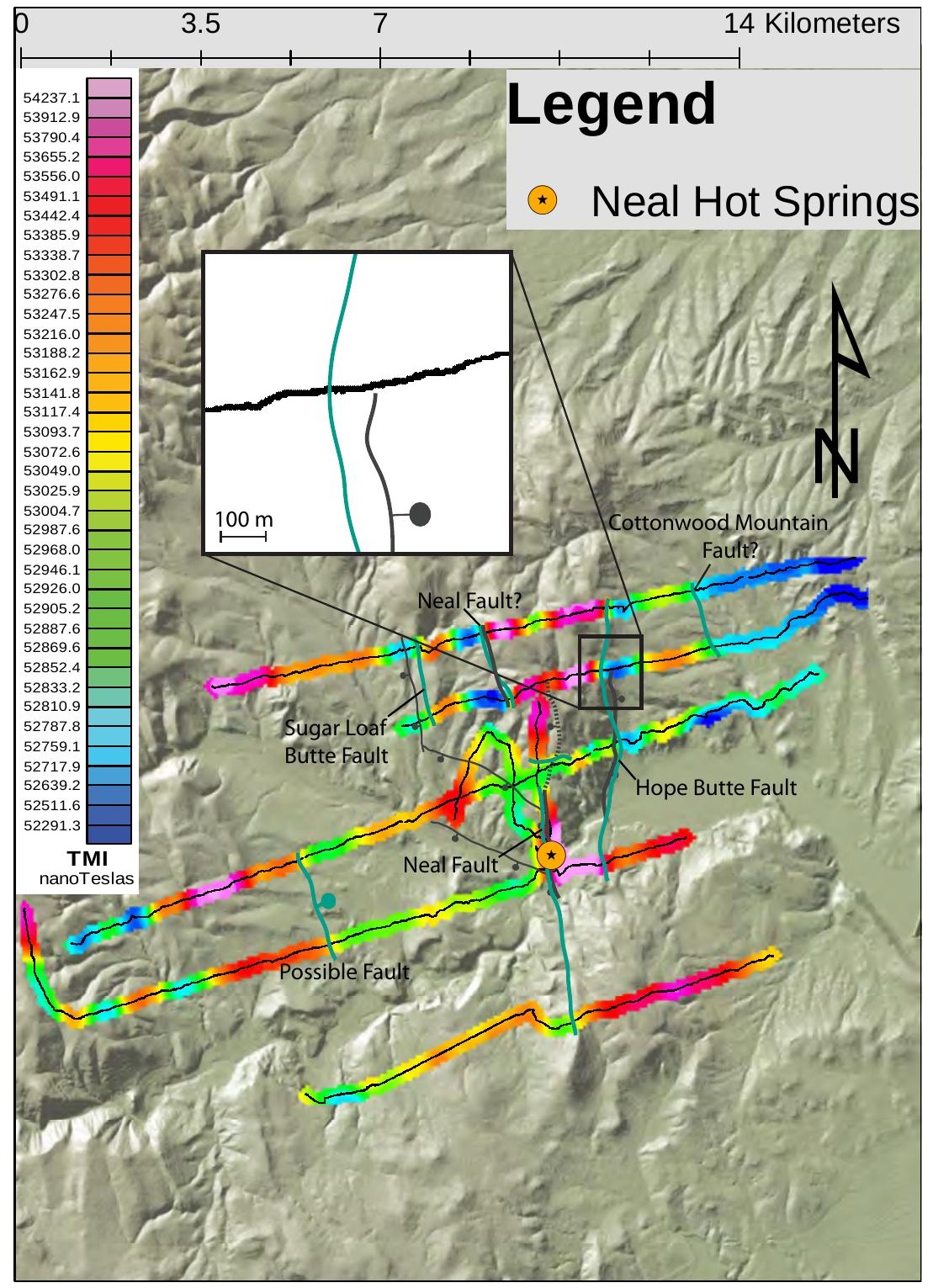

Figure 3.5: TMI map of NHS with magnetic stations shown in black. Interpreted steepest gradients that show similar anomaly shape and continue through multiple lines are interpreted as faults and are shown in green. Grey lines are density contacts located with gravity data. 


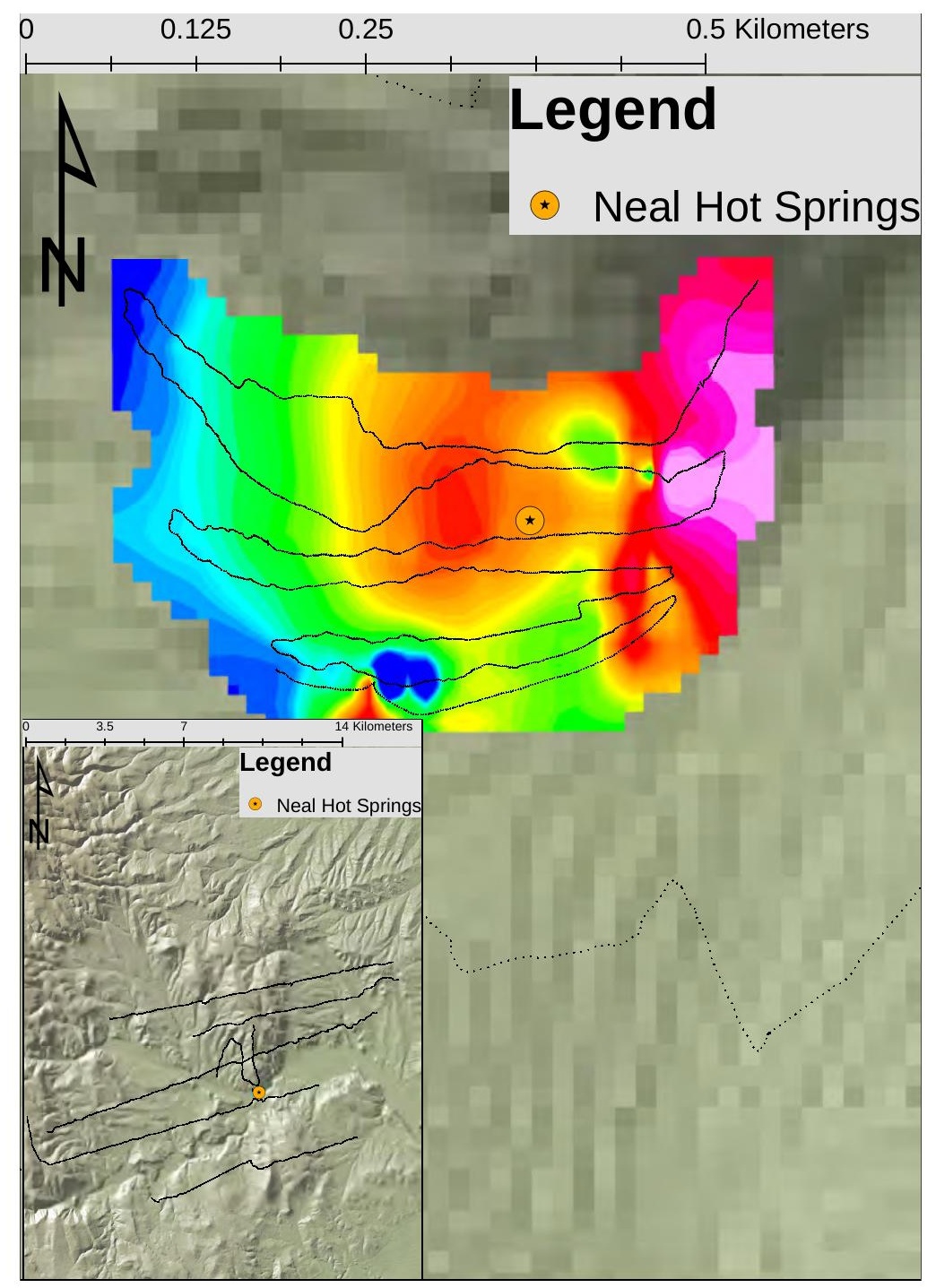

Figure 3.6: TMI map of the surface springs at NHS with magnetic stations shown in black. This survey is roughly the size of the orange circle in the inset. The springs fall within a magnetic high. This anomaly is suggestive of geochemical conditions that are preserving and/or creating magnetic minerals. This is an oddity in that many geothermal fields exhibit a magnetic low over the geothermal site from geothermal water degradation of magnetic minerals ((Cumming, 2009; Hunt et al., 2009)). The strong dipolar anomaly in the southwest is caused by a small building. 


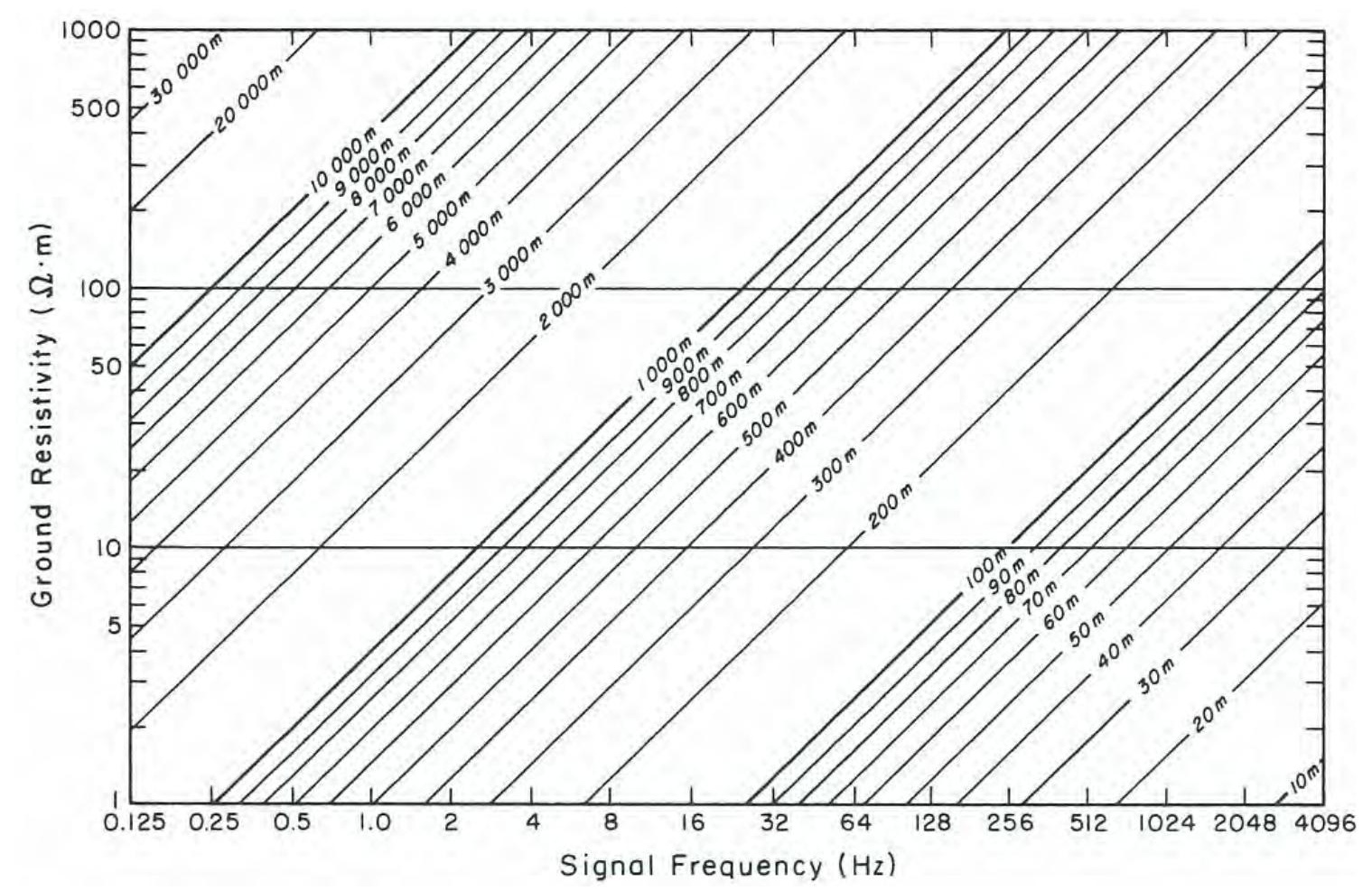

Figure 3.12: Skin depth $(\delta)$ as a function of ground resistivity $(\rho)$ and frequency $(f)$ from Zonge and Hughes (1991). Note that for NHS data, a frequency of 16 hertz and ground resistivity of about $20 \Omega \cdot m$ makes for a skin depth of 500 meters. 


\subsubsection{Controlled Source Audiomagnetotellurics}

The scalar controlled source audiomagnetotelluric method is a frequency-domain electromagnetic sounding technique that involves an electromagnetic source (grounded

alternating dipole) and a receiving set of dipole receivers and magnetometer (Zonge and Hughes, 1991). The source dipole is comprised of two grounded insulated wires located a set distance apart. By sending a current of electricity into the ground between the two ends, a dipole electromagnetic field source is created that sends electromagnetic waves propagating outwards from the source in the subsurface. Depth penetration of the electromagnetic waves $(D)$, can be approximated with skin depth $(\delta)$, which is dependent on frequency $(f)$ and subsurface resistivity $(\rho)$ (Zonge and Hughes, 1991).

$$
\begin{aligned}
& \delta=\sqrt{\frac{\rho}{f}} \\
& D=\frac{\delta}{\sqrt{2}}
\end{aligned}
$$

From equation (3.6) I would like to emphasize an important observation. $\delta$ will increase with decreasing $f$ or increasing $\rho$ and is shown in Figure 3.12 for various combinations of these variables. Since ground resistivity is a variable that we cannot alter, to probe at different depths, the dipole orientation is alternated from one end to the other and swept through a series of frequencies.

Measurements of the electric and magnetic fields created by the alternating dipole source are measured in the far-field, plane wave portion of the wavefront for each frequency within the sweep. The electric field phase and amplitude is measured 
parallel to the source dipole with a series of grounded receiving dipoles, and is denoted $E_{x}$. Perpendicular to $E_{x}$, a magnetometer measures the magnetic field amplitude and phase $\left(B_{y}\right)$. For a homogeneous earth, the ratio of these perpendicular field components gives the apparent resistivity $(\varrho)$ in the following relation (Zonge and Hughes, 1991)

$$
\varrho=\frac{1}{\mu \omega}\left|\frac{E_{x}}{B_{y}}\right|^{2}
$$

where $\mu$ is the magnetic permeability and $\omega$ is the angular frequency. After finding $\varrho$ for each frequency at every dipole receiver, one compiles a vertical section of the $\varrho$ structure beneath each receiving dipole. The vertical section is then inverted to find a true resistivity model of the subsurface for interpretation. For a more complete description of the method see Cagniard (1953); Zonge and Hughes (1991).

At the NHSR, a line of scalar CSAMT data were gathered south of the surface springs to investigate the location of geothermal waters and Neal fault beneath quaternary fill (Figure 3.1). The source dipole had an offset of 815 meters, and was located $15 \mathrm{~km}$ north of the CSAMT line. Normally one places the source dipole at a distance that is four times the desired $\varrho$. At NHS, this distance was eight to ten kilometers. However due to rough terrain and access issues, the source was placed $15 \mathrm{~km}$ north of the CSAMT line. A current of 5.5 amps was passed between the source electrodes. Data were collected at frequency steps that doubled with each step for frequencies from one Hertz through $8192 \mathrm{Hertz}(\mathrm{Hz})$. The receiving dipoles were spaced at 50 meters between grounded electrodes. Data were collected with four active receiving dipoles per frequency sweep, and instantaneous readings at each frequency were summed (stacked). The number of stacked readings increased from 
eight at one $\mathrm{Hz}$ to 8192 at $8192 \mathrm{~Hz}$, doubling with each step up in frequencies.

Due to low signal to noise for frequencies below $16 \mathrm{~Hz}$, I calculated an apparent resistivity pseudosection from the raw data using frequencies above $16 \mathrm{~Hz}$ (Figure 3.13). The low signal to noise is likely due to a source receiver offset that was too large. Inversion of the apparent resistivity section for true resistivity was performed with ZONGE data processing SCS2D version 3.0 inversion software. This inversion scheme minimizes model and data misfit with the root mean square method. The inversion segregates the subsurface into a grid of pixels, each with its own resistivity. Each pixel's resistivity is iteratively adjusted until the root mean square error is minimized between the model and observed data's apparent resistivity and phase measurements.

I interpret inverted CSAMT data at the NHSR to identify the Neal fault, and a zone of low resistivity associated with geothermal waters (Figure 3.14). The westdipping Neal fault separates an area of low resistivity to the west from a zone of higher resistivity. The higher resistivity unit represents the Hog Creek sequence, which is exposed at the surface (Figuire 2.9). The block west of the Neal fault contains a stratified resistivity section. Higher resistivity sediments overlie the down-dropped Hog Creek volcanic section (identified in a nearby borehole). The low resistivity Hog Creek sequence west of Neal fault shows a resistivity contrast with the same rocks just east of the Neal fault. I interpret this lowered resistivity to be caused by geothermal alteration of the rock and/or the presence of geothermal waters. Richards et al. (2010) point out that thermal fluids can significantly decrease resistivity. Therefore, one interpretation of the low resistivity zone is that geothermal waters have migrated up the Neal fault along a series of fractures. When the waters impact the interface between less permeable sediments and fault fractured volcanic rocks of the Hog Creek 


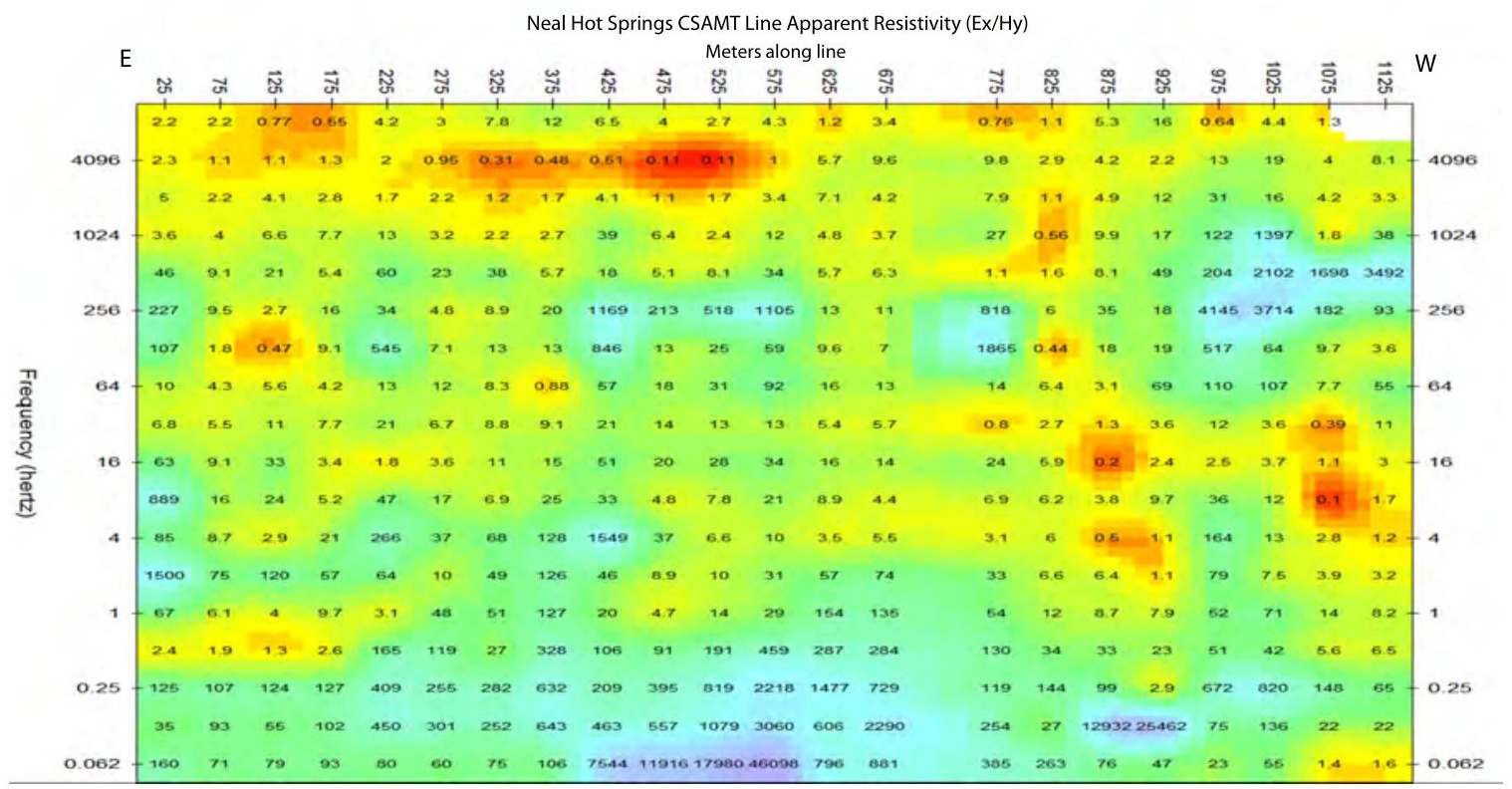

Figure 3.13: Apparent resistivity pseudosection for the frequencies between 16 and 8192 hertz. The location of this line is shown in Figure 3.1.

sequence,a portion of that water is forced laterally into the Hog Creek sequence and is responsible for the broad zone of lowered resistivity. Cumming (2009) describes geothermal waters altering rocks and breaking them down into clays. This clay layer is extremely conductive, and could also manifest itself as the broad resistivity low. In either scenario, geothermal waters are ultimately responsible for the observed resistivity low. It is important to note that a nearby borehole located west of the Neal fault and 250 meters away from the survey indicates a change in lithology from sediments to the Hog Creek sequence and temperature spike of $15.5^{\circ} \mathrm{C}$ at 350 meters depth. Both observations correlate with the above interpretations. 


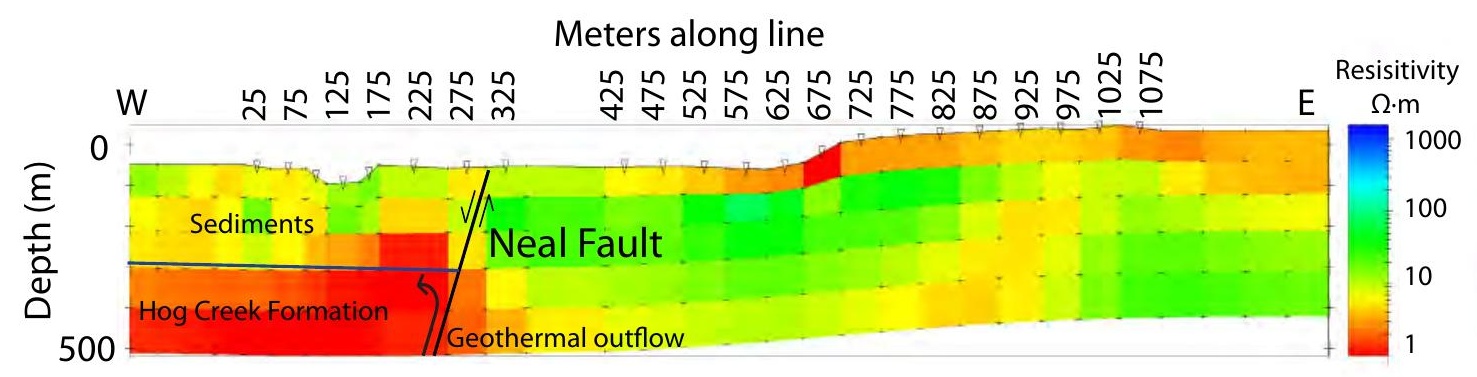

Figure 3.14: Inverted resistivity pseudosection for the frequencies between 16 and 8192 hertz. The Neal fault is interpreted at the intersection of extreme low resistivity and moderate resistivity Hog Creek volcanics on the western edge of the map. The zone of low resistivity to the west is caused by geothermal water infiltration into the down-dropped Hog Creek sequence. This infiltration has done one of two things. Either the volcanics have been altered into a highly conductive clay cap on top of the geothermal reservoir, or geothermal waters are directly being imaged as they migrate laterally through the brecciated Hog Creek sequence. This low resistivity zone is overlain by more resistive sediments. 


\section{CHAPTER 4: DISCUSSION}

\subsection{Introduction}

My interpretations from the geophysical data help describe geological structures and geothermal water distributions at the NHSG. To form a three-dimensional model of the subsurface permeability distribution, I assumed that faults are the only permeable pathways of interest. With this assumption, I integrated interpretations from each geophysical technique into a single cohesive three-dimensional model of the subsurface permeability at the NHSG. Within this section I first discuss my integration of each dataset into a conceptual model for the NHSG that presumes tectonic faulting is an important control on permeability that produces conduits for fluid migration and juxtapositions of lithologies with contrasting intrinsic properties. I then test the conceptual model with a set of gravity models that orthogonally traverse the production zone. These gravity models refine the conceptual model of the NHSG into a final working model; a detailed three-dimensional subsurface model created from the joint interpretations of the geophysical, geologic, and borehole data from the NHSR.

\subsection{Geophysical Data Integration}

To simplify the data integration, I first break the NHSR into western and eastern zones as seen in Figure 4.1. This division splits the study area into a western por- 
tion that houses the NHSG and an eastern portion that contains the Cottonwood Mountain fault. The main geologic structures and stratigraphy within the eastern section is characterized with vibroseis, gravity, magnetic, passive seismic, and surface geologic datasets. Interpretations from vibroseis and magnetic data locate the eastdipping normal-slip, Cottonwood Mountain fault (Figure 4.2). Knudsen et al. (1994) suggested the Cottonwood Mountain fault is a network of sub-parallel faults. I propose that the fault I identify is a splay or strand of the Cottonwood Mountain fault system and that Edwards (2013) mapped another strand of the same fault system located $0.5 \mathrm{~km}$ to the east. Therefore, within the NHSR and directly north of the Bully Creek Reservoir, my interpretation is consistent with the Knudsen et al. (1994) interpretation that strain along the Cottonwood Mountain fault is accommodated via a number of large en echelon faults.

I interpret the location of the roughly 60 degree, east-dipping normal-slip Hope Butte fault from vibroseis, magnetic, gravity, and geologic data (Figure 4.2). This fault is located roughly $3.2 \mathrm{~km}$ west of the interpreted Cottonwood Mountain fault. I interpret offsets greater than 500 meters in 15 Ma Hog Creek sequence, resulting in an average slip of $\sim .03 \frac{m m}{y r}$ across the Hope Butte fault. The presence of surface warm springs along the Hope Butte fault suggest the fault may still be active due to fault movement keeping permeable zones cleared of mineral precipitation from geothermal fluids (Curewitz and Karson, 1997). Magnetic, gravity, and geologic data interpretations define the north-striking Hope Butte fault as it continues across the NHSR. Interpretations from vibroseis data locate the east dipping reverse slip Bully fault (Figure 4.2). The Bully fault was previously unidentified, and represents an important discovery for understanding interactions between the Hope Butte fault and 
the Cottonwood Mountain fault. I interpret the Bully fault and associated folding of the Hog Creek volcanic package as a compressional accommodation zone resulting from differential slip along the Hope Butte and Cottonwood Mountain faults. This suggests contemporaneous fault motion and that the Hope Butte fault is potentially active. Should this be the case, there may be geothermal prospects along the Hope Butte fault.

I incorporated geologic, borehole geochemical, and numerous geophysical imaging techniques to characterize major tectonic faults of the western section of my study area. Interpretations from gravity, magnetic, hammer seismic, and CSAMT data locate the west-dipping, normal-slip Neal fault (Figure 4.3). Near NHS, magnetic, gravity, and hammer seismic data define the surface contact of the fault. Similarly, magnetic, gravity, and CSAMT data isolate the surface contact for the Neal fault nearly $0.3 \mathrm{~km}$ south of the surface springs. From these observations, I interpret a western bend in the Neal fault. Seismic data indicate the Neal fault is dipping roughly $60^{\circ}$ to the southwest. Interpretations from CSAMT data indicate a zone that likely denotes the top of a geothermal water reservoir at a depth of 300 meters. Borehole data corroborate this interpretation. At NHS, direct current resistivity and self-potential data image near surface geothermal waters, and indicate that these waters are migrating upward along the Neal fault in the subsurface. Interpretations from gravity and magnetic data map the Neal fault along strike to the north and south of NHS, and show that the Neal fault is continuous for at least seven kilometers. Interpretations from magnetic and gravity data map the Sugar Loaf Butte fault as a westerly dipping structure to the west of the NHSG. This structure does not intersect with geothermal fluid production in the area. Interpretations from gravity data 
suggest two southerly dipping, blind tectonic structures, the Coyote fault and the Cottonwood Creek fault. The Cottonwood Creek fault is also imaged in vibroseis line 2 as a south-dipping structure with an average slip of $\sim .003 \frac{\mathrm{mm}}{\mathrm{yr}}$. These two structures bisect the NHSG, and are identified in borehole observations as zones of significant permeability due to loss of drilling fluid circulation. By defining lost circulation zones as faults, and connecting these fault traces to density contacts derived from HGM gravity data, I define two south-dipping $60^{\circ}$ faults. In map view, the Cottonwood Creek and Coyote faults intersect both the Neal fault and Sugar Loaf Butte fault at an angle near to normal. It has been suggested by Edwards (2013) that these two blind structures represent hard linkage between the Neal fault and Sugarloaf Butte fault. If this is the case, then all four faults must have contemporaneous motion. This suggests that significant permeability could be found along the Sugarloaf Butte fault and may be a future exploration target.

Every geothermal system needs a heating mechanism to warm subsurface waters. At the NHSG, tectonically thinned crust from the numerous extensional regimes increases geothermal gradients by bringing hot mantle material closer to the surface. However, this is likely not the sole source of heat at the NHSG. One deep borehole within the NHSG intersects a large Jurassic granitic body of the Blue Mountain Olds-Ferry-Izee terrane at a depth of 2087 meters depth to total well depth of 2472 meters. Costain et al. (1980) show that the decay of radiogenic isotopes within granites can produce the heat energy required to raise subsurface water temperatures for geothermal use. The presence of a large body of granite in the subsurface at the NHSG provides an additional source of heat. Assuming an average composition of granite, the heat production for the granite body underneath the NHSG is $2.5 \frac{\mu W}{m^{3} s}$ 
(Haenel et al., 1988). With the minimum thickness of the granite body at 328 meters, and assuming a minimal areal extent equal to that of the NHSG (3 by 8 kilometers), a total heat production of $19,680 \frac{\mu W}{m^{3} s}$ is possible. The amount of this energy trapped in the subsurface is dependent upon many factors not explored in this thesis. However, the granite body likely provides an additional heat source at the NHSG.

Shaltry et al. (2013) identified three seismic events within the NHSR from a passive seismic dataset collected with a network of broadband seismometers. These events are likely related to motion on the Cottonwood Mountain fault, Hope Butte fault, and Neal fault. Events such as these arise from slip along the fault surface, and provide further evidence that these faults are active. fault activity is important because it provides the mechanism for keeping subsurface permeable pathways clear for geothermal fluid circulation (Curewitz and Karson, 1997).

The conceptual model I have developed for the NHSG is based on four major tectonic faults. The Neal fault provides the main conduit for waters to migrate to the surface. The Neal fault is hard linked with the Sugar Loaf Butte fault via two subsidiary faults, the Cottonwood Creek and Coyote faults. All of these faults are extensional, possibly active, and potentially provide permeable pathways for fluid migration in the subsurface. Geothermal waters in the area are heated with the combined thermal energy from elevated geothermal gradients due to tectonically thinned crust and the presence of a granitic body in the subsurface. Near the NHS, the top of the geothermal reservoir likely sits at 300 meters depth and at this depth is likely housed within a fractured Hog Creek volcanic package along the Neal fault. 


\subsection{Gravity Modeling}

I created two gravity models to test my conceptual model of the NHSG (Figure 4.1). Gravity modeling involves building a subsurface density distribution model and calculating a theoretical gravity field from the density distribution. This forward model is then compared to the Complete Bouguer Anomaly gravity values along the profile. The goal is to minimize the error between the computed and observed gravity fields by altering the subsurface model's rock unit density distribution in a way that respects known geologic constraints and provides a geologically reasonable model of the subsurface. The final step in my modeling flow was to invert the differing rock units for density using an Ordinary Least Squares inversion scheme to minimize the error in observed and calculated gravity (e.g., Blakely, 1995). Gravity modeling is an inherently non-unique mathematical problem; this means that there exist an infinite number of density distributions that can match the observed field. Therefore, at the NHSG, I incorporate geologic constraints derived from the other geophysical methods and borehole measurements to develop a realistic tectonic model of the subsurface. Geologic unit thicknesses were derived from borehole measurements, and these thicknesses are allowed to vary according to borehole logs. Rock densities were derived from the direct measurement of hand samples collected from outcrops in the NHSR and from accepted rock property values for each given rock type and were not allowed to deviate outside of these values. fault dip and location were derived from the combination of Edwards (2013) geologically mapped contacts and my geophysically interpreted locations. Offset of units across faults were constrained by seismic reflection data where available, borehole information, and by gravity anomaly size and shape where no other information was available. 
During my gravity modeling process, I began with a model derived directly from my previously developed conceptual model for the area (see section 4.2). Gravity model A-A' lies along an east-west transect across the NHSR. The original conceptual model that I developed in section 4.2 along A-A' did not include a westerly dipping normal fault. This difference became apparent when I incorporated borehole information into the gravity model. A large offset of the Hog Creek Sequence necessitated the existence of a fault, which is best explained by the southern extension of the Sugar Loaf Butte fault (Figure 4.4). The central and eastern portions of the model fit observed data well, within $\sim .2$ milliGals. However, the western portion of the original gravity model produced errors between the observed and calculated gravity fields of $\sim .75$ milliGals. Within the blue circle shown in Figure 4.4, the gravity model does not incorporate a high density body in the subsurface. A number of boreholes intersect the previously unknown Neal Basalt in this region of the gravity model. I interpret the circular gravity high with a diameter of $1 \mathrm{~km}$ (shown in Figure 3.4 as a blue circle) as the expression of a circular Neal Basalt volcanic flow with a neck that travels along the Sugar Loaf Butte fault. The western end of the gravity model produces a calculated gravity field that exceeds observed values. Therefore, the original model was modified to incorporate less dense rock. By including a western dip into the Hog Creek Sequence and thickening the package of sediment above it, the error between the observed and calculated gravity was reduced from .957 milliGal to .323 milliGal. Therefore, my final model incorporates the Sugar Loaf Butte fault, volcanic vent and small Neal basalt flow, and gives the Hog Creek Sequence a westerly dip and thicker sedimentary package (Figure 4.4).

Gravity model B-B' lies along a transect that is oriented north to south across 
the NHSR. The original model tested can be seen in Figure 4.5. This model clearly contains some discrepancies between the calculated and observed gravity fields. The modeled Coyote fault creates an anomaly that does not reflect the size nor shape of the observed field. If observations from seismic line 2 are incorporated into the model and the Hog Creek sequence forms a southerly dipping monocline, a much better fit to the observed field can be had (Figure 4.5). Therefore, the interpreted Coyote fault contact defined by the gravity method highlighted the folding of the Hog Creek sequence as it dips to the south, and is not a fault. A short wavelength gravity anomaly highlighted in Figure 4.5 represents a localized zone of near surface high density material. During modeling, the best fit to observed gravity was to place a vent feature directly beneath this anomaly. Therefore, one interpretation of this small gravity high is that this is the location for a volcanic vent of the Vines Hill andesite. One other important conclusion from modeling is that the sediment fill must thicken to the south along the profile B-B'. A surface map highlighting my final interpretations can be seen in Figure 4.6.

\subsection{Three Dimensional Subsurface Model}

The final step in integrating the available geophysical and geologic datasets is to create a subsurface three-dimensional map of potential permeability zones. Cumming (2009) stressed the importance of developing such a model so all subsurface information can be seen in a concise and interactive manner to guide future exploration and development of the field. For the NHSG I used Geosoft's Target software to integrate datasets in oreder to identify potential major permeability zones in the subsurface. I assume that major permeability zones exist along the actively slipping tectonic fault 
zones, and therefore emphasize mapped and imaged faults within the field (Curewitz and Karson, 1997). My final three-dimensional subsurface permeability model for the NHSG is shown in Figure 4.7 and Figure 4.8. When integrating all discussed methods, I identify the Neal, Cottonwood Creek, and Sugar Loaf Butte faults as zones where significant permeability is possible. Through the use of geophysical imaging techniques, the Cottonwood Creek fault was discovered, and the Sugar Loaf Butte fault has been extended 1.5 kilometers to the south. These two tectonic structures could provide future targets for increased production at the NHSG. Gravity modeling indicates that the Coyote fault likely does not exist, and that a fold in the Hog Creek sequence occurs within the NHSG. Price (1966) indicates that fracturing occurs at fold hinges within rock packages. Therefore, a permeable zone may exist along the fold hinge within the Hog Creek Package along the northern portion of the NHSG, and potentially within the underlying Basalt of Malheur Gorge.

\subsection{Regional Implications}

I characterize faults that were formed through regional extension. Due to the large offset and general northerly trend of the Neal fault and Hope Butte fault, I suggest these faults were part of OIG extension. They were later cut by the northwesterly trending Cottonwood Mountain fault, which at the time represented movement associated with the opening of the WSRP. The VFZ originally defined the western limit of the WSRP, but recent dextral movement along the VFZ is likely related to Basin and Range extension (Lawrence, 1976). This movement reactivated the Cottonwood Mountain, Hope Butte, and Neal faults. According to Payne et al. (2012), strain within eastern Oregon is small. I believe this suggests strain in eastern Oregon must 
be accommodated via pre-existing zones of lithospheric weakness such as the Cottonwood Mountain, Hope Butte, and Neal faults. This interpretation has significant regional implications for locating future geothermal resources in the surrounding area in that it isolates exploration to places with substantial and intersecting faults along the currently deforming VFZ. In order to assure enough thermal energy to heat subterranean waters, these active fault intersections should fall within the zone of high heat flow shown in Figure 2.4. Using these criteria for locating a potential geothermal resource, I would suggest the active Juniper Mountain fault as a potential geothermal target. The Juniper Mountain fault intersects the Cottonwood Mountain fault roughly $30 \mathrm{~km}$ north of NHS and falls within the zone of high heat flow surrounding the NHSR (e.g., Personius, 2002). 


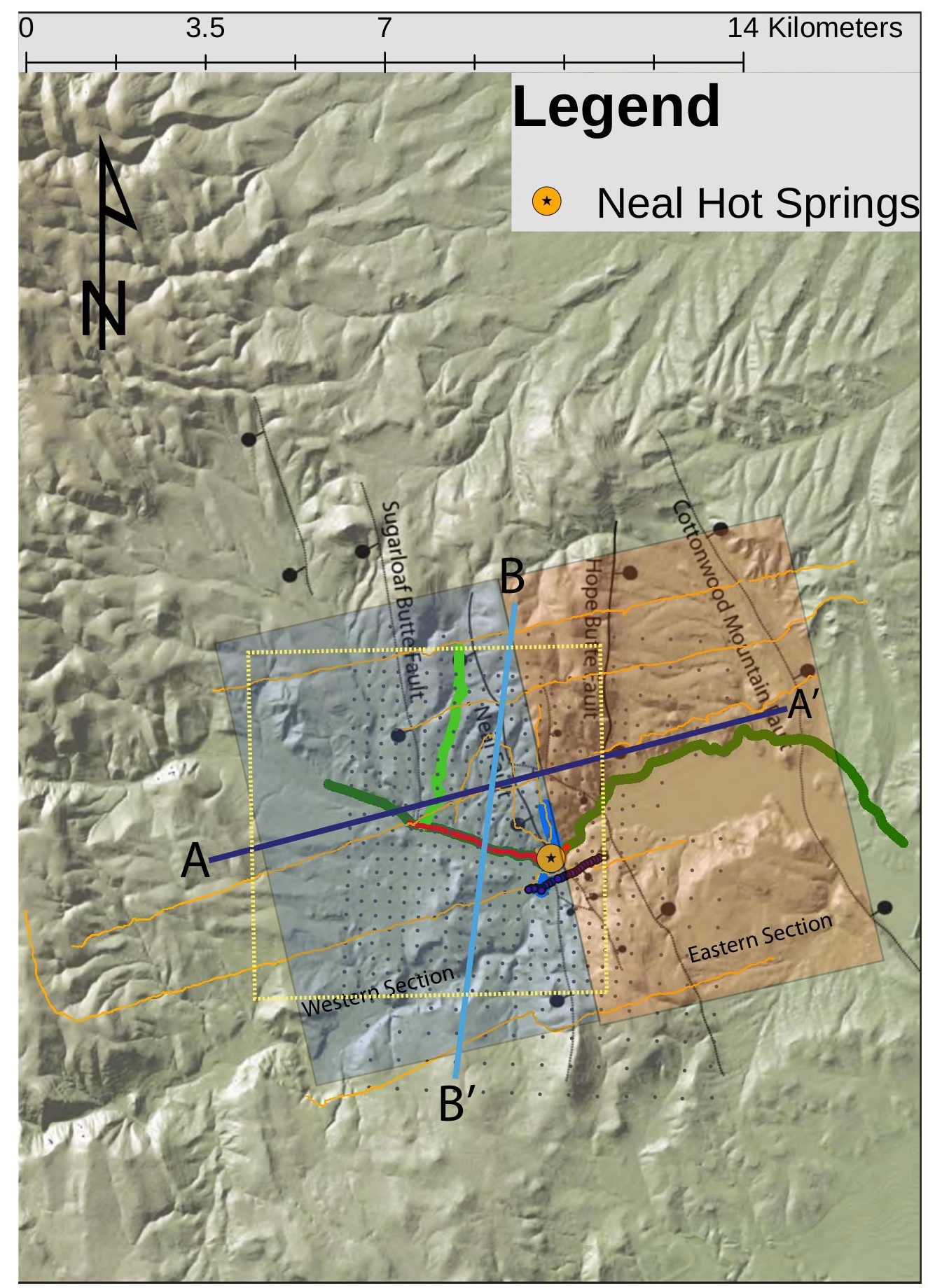

Figure 4.1: The NHSR with the locations for all the geophysical methods broken down into western and eastern sections. Modelled gravity profiles are shown as A-A' and B-B' with the final three-dimensional model's outline shown with a tan dashed line. 


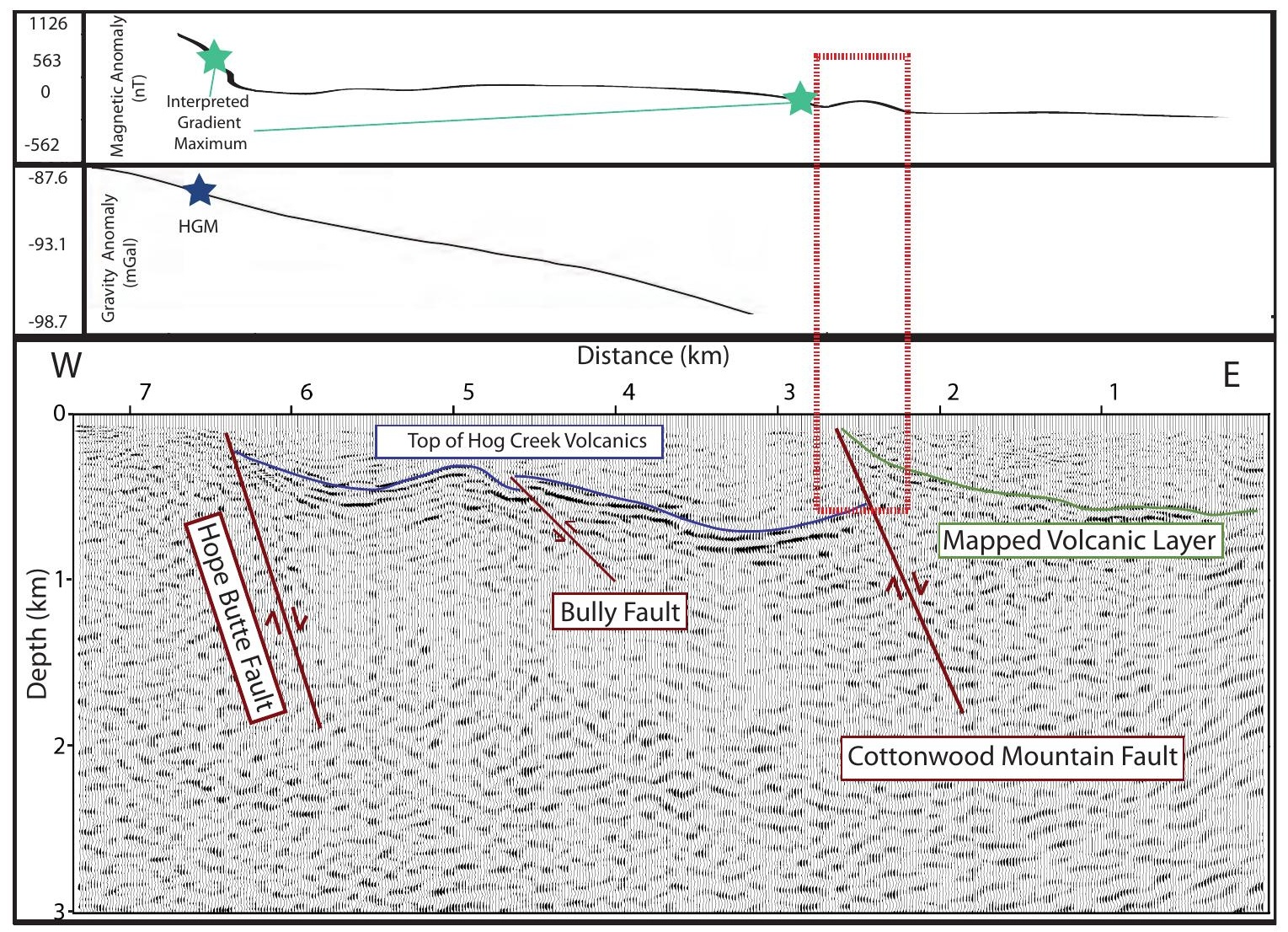

Figure 4.2: Interpreted vibroseis, gravity and magnetic datasets within the eastern zone. 

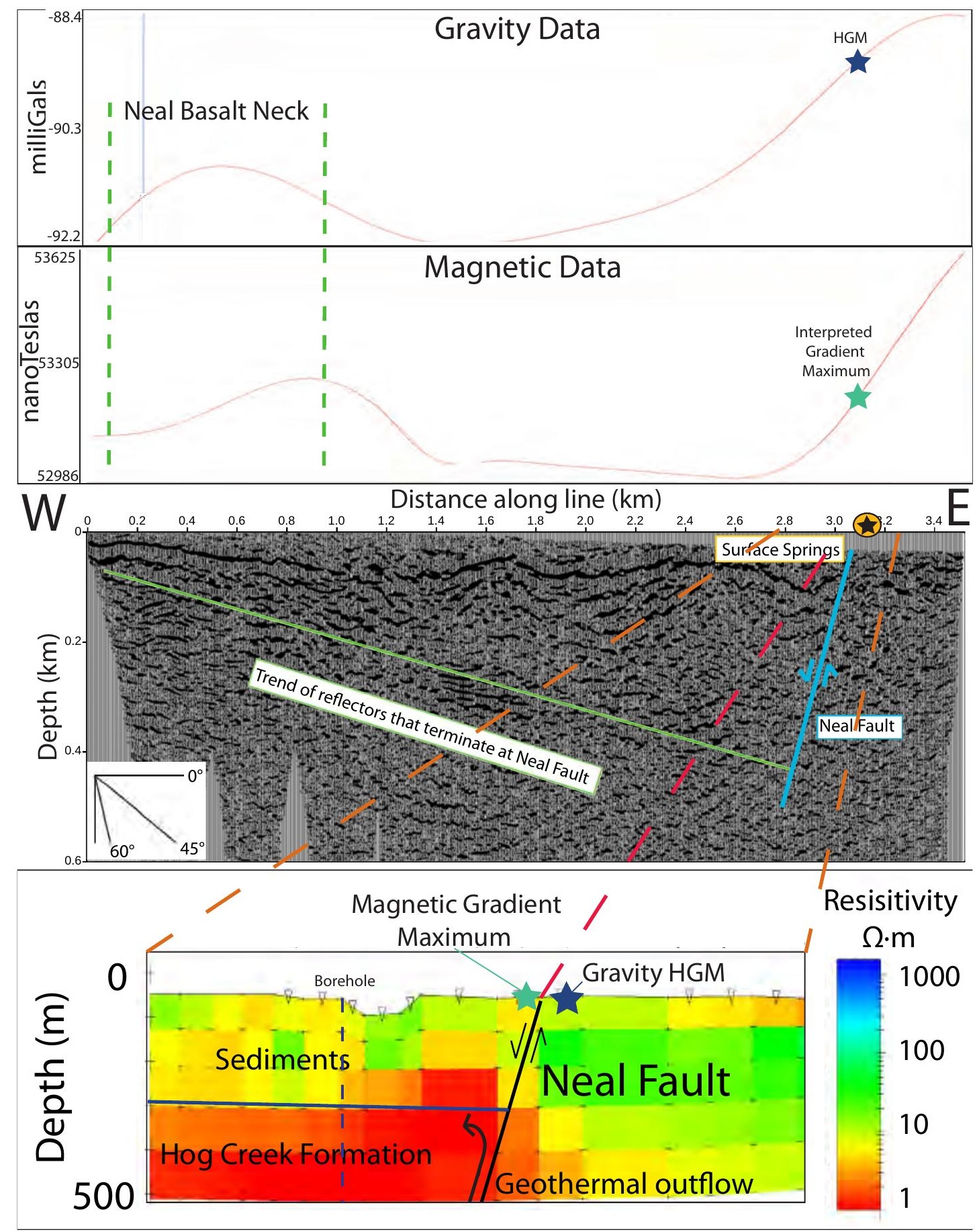

Figure 4.3: Interpreted hammer seismic, gravity, magnetic, and CSAMT datasets within the western zone. 


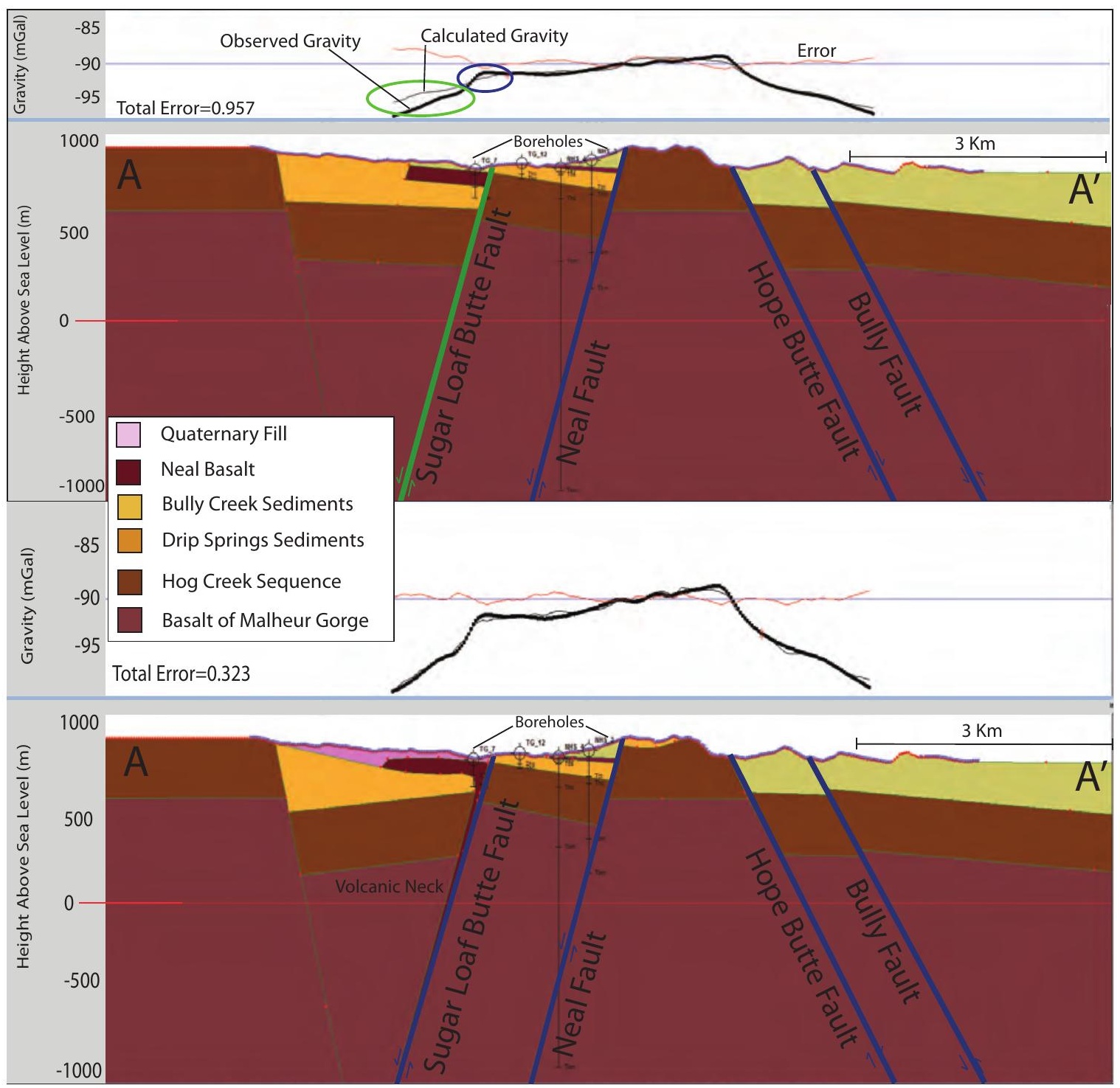

Figure 4.4: Gravity model A to A'. The original model tested is shown on top, with the lower model being my final interpretation. 


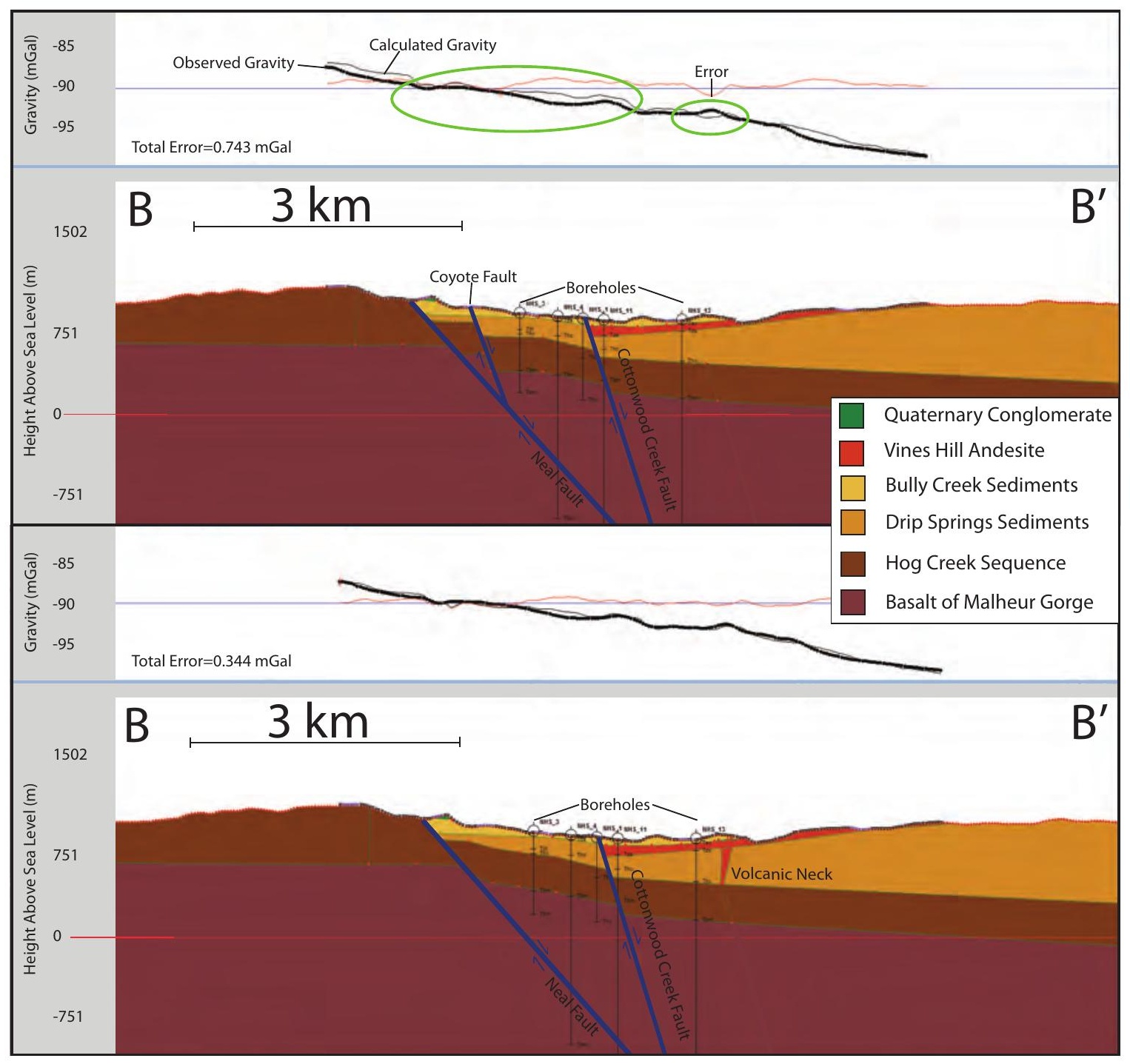

Figure 4.5: Gravity model B to B'. The original model tested is shown on top, with the lower model being my final interpretation. 


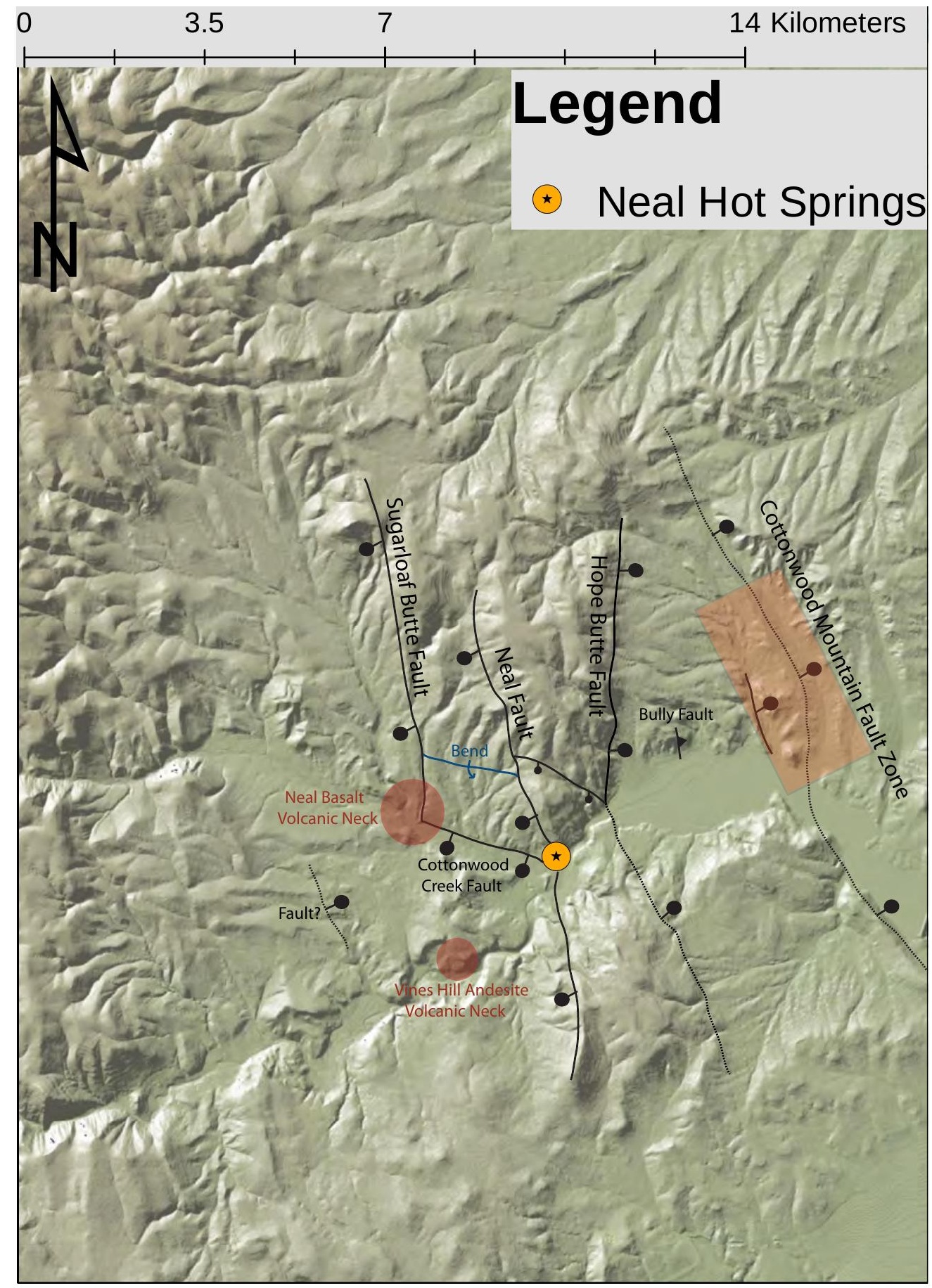

Figure 4.6: An overview map of the NHSR depicting my major structural and geologic interpretations. 


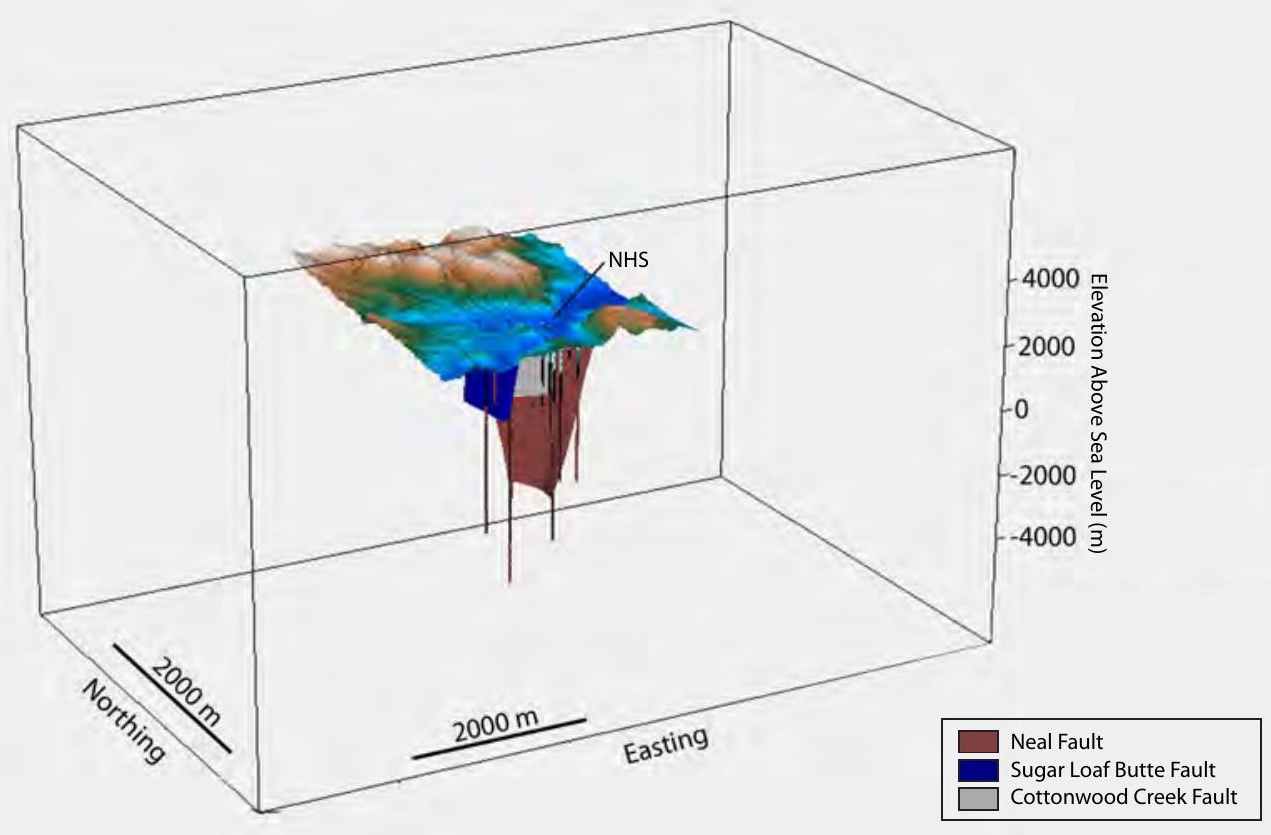

Figure 4.7: The final three-dimensional subsurface model for the NHSG showing borehole locations and faults as a proxy for permeability. 


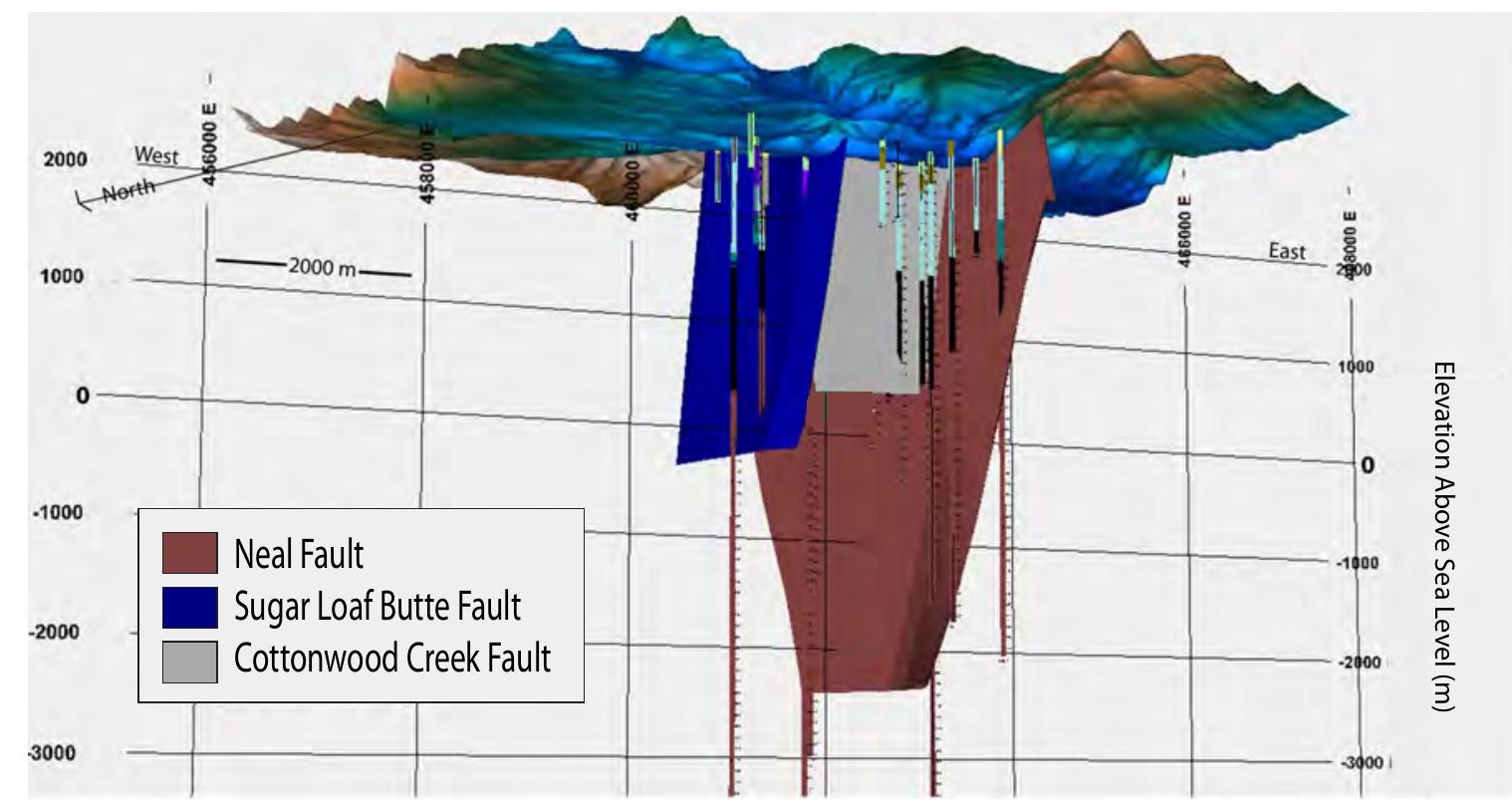

Figure 4.8: The three-dimensional subsurface permeability model at the NHSG as seen from below the surface. 


\section{CHAPTER 5: CONCLUSIONS}

\subsection{Conclusions}

The main goal of this study was to show that a geophysically intensive exploration program can provide important subsurface information to constrain the location of potential permeable zones, the target of every geothermal drilling program. This was motivated by the high production costs related to the risks of drilling into a subsurface permeability distribution that is poorly defined with geologic and sparse geophysical datasets. A secondary goal was to highlight that while a study such as mine might be viewed by the industry as expensive, if it kept one exploration well from being drilled, the money saved more than justifies a geophysically robust subsurface exploration.

By investigating the geologically and geophysically complex NHSG, I have shown that an integrated geophysical exploration provides detailed subsurface permeability and geothermal fluid information. I must stress that without the integrated interpretation of numerous geophysical techniques, my results would not be conclusive. By

developing a three-dimensional model for subsurface permeability, I have provided a concise description of subsurface geothermal target zones that may guide future exploration within the NHSG.

Much of any geothermal field's budget is spent on drilling. This will continue to be one of the highest risks in developing a field and must be mitigated if geothermal energy is to become a focal point for national energy production. I have shown at 
the NHSG that a geophysically driven exploration program provides a model for the subsurface distribution of potential permeable zones. If this approach is executed prior to the drilling program's initiation, the number of necessary boreholes could be reduced through a targeted, quantitatively-driven drilling program.

\subsection{Future Work}

Additional work that could be used to improve the characterization of the NHSG would include three expansions on current datasets. By gathering enough magnetic data to create more continuous coverage within the NHSR, fault locations could be made with greater detail and comparisons between the gravity data and magnetic data would be possible throughout the field. This would allow for the testing of gravity interpretations on fault locations with magnetic interpretations. Near offset vibroseis data within the NHSG could provide the requisite seismic energy needed for greater depth penetration, therefore providing an improved image of the producing zone within the NHSG. This would better constrain the location of production scale permeability for use in other areas of the field. Lower frequency CSAMT data, and more complete coverage of the NHSG could image the geothermal reservoir's lateral extent in the subsurface, and provide better depth constraints on the location of geothermal waters. This information would be important for understanding reservoir dynamics, as well as any future well placements when combined with permeability information. 


\section{REFERENCES}

Bankey, V., Cuevas, A., Daniels, D., Finn, C.A., Hernandez, I., Hill, P., Kucks, R., Miles, W., Pilkington, M., Roberts, C., Roest, W., Rystrom, V., Shearer, S., Snyder, S., Sweeney, R., Velez, J., Phillips, J.D., and Ravat, D. 2002. Digital data grids for the magnetic anomaly map of North America: U.S. Geological Survey Open-File Report 02-414. Tech. rept. U.S. Geological Survey.

Barbier, E. 2002. Geothermal energy technology and current status: an overview. Renewable and Sustainable Energy Reviews, 6(1-2), 3-65.

Blackwell, D.D. 1978. HEAT FLOW OF OREGON. Oregon Department of Geology and Mineral Industries Special Paper, 4, 1-42.

Blackwell, D.D., Leidig, M., and Smith, R. 2002. Regional Geophysics of the Dixie Valley Area : Example of a large Basin and Range Geothermal Resource. Geothermal Resources Council Transactions, 26, 519-522.

Blakely, R.J. 1995. Potential Theory in Gravity and Magnetic Applications. Cambridge University Press.

Blakely, R.J., and Simpson, R. 1986. Approximating edges of source bodies from magnetic or gravity anomalies. Geophysics, 51, 1494-1498.

Briggs, I. 1974. Machine Contouring Using Minimum Curvature. Geophysics, 39(1), $39-48$.

Bujakowski, W., Barbacki, A., Czerwiska, B., Pajk, L., Pussak, M., Stefaniuk, M., 
and Trzeniowski, Z. 2010. Integrated seismic and magnetotelluric exploration of the Skierniewice, Poland, geothermal test site. Geothermics, 39(1), 78-93.

Burchfiel, B.C., Cowan, D.S., and Davis, G.A. 1992. Tectonic overview of the Cordilleran orogen in the western United States. Chap. 8, pages 407-479 of: The Geology of North America. The Geological Society of America.

Burger, H., Sheehan, A., and Jones, C. 2006. Introduction to Applied Geophysics. W.W. Norton and Company.

Cagniard, L. 1953. Basic Theory of the Magneto-Telluric Method of Geophysical Prospecting. Geophysics, 18, 605-635.

Camp, V. E., and Hanan, B. B. 2008. A plume-triggered delamination origin for the Columbia River Basalt Group. Geosphere, 4(3), 480.

Camp, V.E., and Ross, M.E. 2004. Mantle dynamics and genesis of mafic magmatism in the intermontane Pacific Northwest. Journal of Geophysical Research, 109, 1-14.

Christensen, N.I., and Mooney, W. 1995. Seismic velocity structure and composition of the continental crust: A global view. Journal of Geophysical Research, 100(B7), $9761-9788$.

Coble, M.A., and Mahood, G.A. 2012. Initial impingement of the Yellowstone plume located by widespread silicic volcanism contemporaneous with Columbia River flood basalts. Geology, 40(7), 655-658.

Colwell, C., VanWijk, K., Liberty, L., Warren, I., and Revil, A. 2012. Integrated geophysical exploration of a known geothermal resource: Neal Hot Springs. Chap. 272, pages $1-5$. 
Corwin, R.F., and Hoover, D.B. 1979. The self-potential method in geothermal exploration. Geophysics, 44(2), 226-245.

Costain, J.K., Glover, L., and Sinha, A.K. 1980. Low-Temperature Geothermal Resources in the Eastern united States. EOS, 61(1), 1-4.

Cross, J., and Freeman, J. 2009. 2008 GEOTHERMAL TECHNOLOGIES MARKET REPORT. Tech. rept. July. Department of Energy.

Cumming, W. 2009. GEOTHERMAL RESOURCE CONCEPTUAL MODELS USING SURFACE EXPLORATION DATA. In: 34th Workshop on Geothermal Reservoir Engineering.

Cummings, M. L., Evans, J. G., Ferns, M. L., and Lees, K. R. 2000. Stratigraphic and structural evolution of the middle Miocene synvolcanic Oregon-Idaho graben. Geological Society of America Bulletin, 112(5), 668-682.

Curewitz, D., and Karson, J.A. 1997. Structural settings of hydrothermal outflow : Fracture permeability maintained by fault propagation and interaction. Journal of Volcanology and Geothermal Research, 79, 149-168.

Delvaux, D., Kraml, M., Sierralta, M., Wittenberg, A., Mayalla, J.W., Kabaka, K., and Makene, C. 2010. Surface Exploration of a Viable Geothermal Resource in Mbeya Area, Sw Tanzania . Part I : Geology of the Ngozi - Songwe Geothermal System. Pages 25-29 of: Proceedings World Geothermal Conference.

Department of Energy, U.S. Energy Information Administration. 2012. AEO2012 Early Release Overview. Tech. rept. Department of Energy. 
Dickinson, W.R. 2006. Geotectonic evolution of the Great Basin. Geosphere, 2(7), $353-368$.

Dickinson, W.R. 2010. The Basin and Range Province as a Composite Extensional Domain The Basin and Range Province. International Geology Review, 44(November 2011), 37-41.

Eagar, K.C., Fouch, M.J., James, D.E., and Carlson, R.W. 2011. Crustal structure beneath the High Lava Plains of eastern Oregon and surrounding regions from receiver function analysis. Journal of Geophysical Research, 116(June 2010), 1-18.

Edwards, J. 2013. Structural Controls of the Neal Hot Springs Geothermal System, Eastern Oregon. M.Phil. thesis, University of Nevada- Reno.

Edwards, J., and Faulds, J. 2012. Preliminary Assessment of the Structural Controls of Neal Hot Springs Geothermal Field, Malheur County, Oregon. GRC Transactions, 36, 891-895.

Faulds, James E., Coolbaugh, Mark F, Vice, Garrett S., and Edwards, Melissa L. 2006. Characterizing Strucutral Controls of Geothermal Fields in the Northwestern Great Basin: A Progress Report. GRC Transactions, 30, 69-76.

Faulds, J.E., Hinz, N.H., Coolbaugh, M.F., Cashman, P.H., Kratt, C., Dering, G., Edwards, J., Mayhew, B., and Mclachlan, H. 2011. Assessment of Favorable Structural Settings of Geothermal Systems in the Great Basin, Western USA. GRC Transactions, 35, 777-783.

Ferns, M.L., Brooks, H.C., Evans, J.G., and Cummings, M.L. 1993. Geologic map of 
the Vale $30 x 60$ minute quadrangle, Malheur County, Oregon, and Owyhee County, Idaho.

Fouch, M. J. 2012. The Yellowstone Hotspot : Plume or Not ? Science, 40, 479-481.

Fowler, C.M.R., and Holloway, R. 2006. The Solid Earth. Vol. 2. Cambridge University Press.

Fridleifsson, I., Bertani, R., Huenges, E., Lund, J. W., and Ragnarsson, A. 2008. The possible role and contribution of geothermal energy to the mitigation of climate change. Pages 59-80 of: IPCC Scoping Meeting on Renewable Energy Sources.

Geist, D., and Richards, M. 1993. Origin of the Columbia Plateau and Snake River plain : Deflection of the Yellowstone plume. Geology, 21, 789-792.

Glen, J.M.G., and Ponce, D.A. 2002. Large-scale fractures related to inception of the Yellowstone hotspot. Geology, 30(7), 647-650.

Grauch, V.J.S., and Cordell, L. 1987. Short Note Limitations of determining density or magnetic boundaries from the horizontal gradient of gravity or pseudogravity data. Geophysics, 52(1), 118-121.

Haenel, R., Rybach, L., and Stegena, L. 1988. Handbook of Terrestrial Heat-Flow Density Determination. publisher.

Hooper, P., Johnson, J., and Hawkesworth, C. 2002a. A Model for the Origin of the Western Snake River Plain as an Extensional Strike-Slip Duplex, Idaho and Oregon. Idaho Geological Survey Bulletin, 30, 59-67. 
Hooper, P., Binger, G.B., and Lees, K.R. 2002b. Ages of the Steens and Columbia River flood basalts and their relationship to extension-related calc-alkalic volcanism in eastern Oregon. Geological Society of America Bulletin, 114(1), 43-50.

Hooper, P., Camp, V.E., Reidel, S., and Ross, M.E. 2007. The Origin of the Columbia River Flood Basalt Province: Plume versus Nonplume Models. Geological Society of America Special Papers, 430, 635-668.

Hunt, T.M., Bromley, C.J., Risk, G.F., Sherburn, S., and Soengkono, S. 2009. Geophysical investigations of the Wairakei Field. Geothermics, 38(1), 85-97.

Jennejohn, D. 2011. Annual U.S. Geothermal Power Production and Development Report. Tech. rept. April. Geothermal Energy Association, Washington D.C.

Ken, W., and Blackwell, D. D. 1996. Interpretation of Geophysical Data for the Vale, Oregon Geothermal System. Geothermal Resources Council Transactions, 20, $435-438$.

Knudsen, K.L., Wong, I.G., Bott, J.D.J., Weber, G.E., Silva, W.J., and Lettis, W.R. 1994. Seismotectonic evaluation, Agency Valley and Bully Creek Dams, Vale Project, east-central Oregon: Draft Report prepared for U.S. Department of the Interior, Bureau of Reclamation. Tech. rept. Bureau of Reclamation.

Kucks, R.P. 1999. Bouguer gravity anomaly data grid for the conterminous US. Tech. rept. United States Geological Survey.

Langhi, L., and Borel, G.D. 2008. Reverse structures in accommodation zone and early compartmentalization of extensional system, Laminaria High (NW shelf, Australia). Marine and Petroleum Geology, 25(8), 791-803. 
Lawrence, R. 1976. Strike-slip faulting terminates the Basin and Range province in Oregon. Geological Society of America Bulletin, 87(June), 846-850.

Long, C. L., and Kaufmann, H. E. 1980. Reconnaissance geophysics of a known geothermal resource area, Weiser, Idaho and Vale, Oregon. Geophysics, 45(2), $312-322$.

Long, L., and Kaufmann, R. 2013. Acquisition and Analysis of Terrestrial Gravity Data. Cambridge University Press.

McCaffrey, R., Qamar, A.I., King, R.W., Wells, R., Khazaradze, G., Williams, C.A., Stevens, C.W., Vollick, J.J., and Zwick, P.C. 2007. Fault locking, block rotation and crustal deformation in the Pacific Northwest. Geophysical Journal International, 169, 1315-1340.

Mundell, J. A., and Herbert, G. 2010. GEOPHYSICAL IMAGING TO ENHANCE ANALYSIS, DESIGN AND DRILLING OF LARGE-SCALE GEOTHERMAL SYSTEMS. Pages 845-851 of: SAGEEP.

Nabighian, M.N., Grauch, V.J.S., Hansen, R.O., Lafehr, T.R., Li, Y., Peirce, J.W., Phillips, J.D., and Ruder, M.E. 2005. 75th Anniversary Historical development of the gravity method in exploration. Geophysics, 70(6), 63-89.

Niewendorp, C. 2011. Geothermal Information Layer for Oregon-Wells. Tech. rept. Oregon Department of Geology and Mineral Industries.

Nissen, S., Rundle, K., Lockhart, R., and Morrison, E. 2003. 3-D Seismic Applications by Independent Operators in Kansas. Tech. rept. Petroleum Technology Transfer Council. 
Parasnis, D.S. 1996. Principles of Applied Geophysics. Springer.

Payne, S.J., McCaffrey, R., King, R.W., and Kattenhorn, S.A. 2012. A new interpretation of deformation rates in the Snake River Plain and adjacent basin and range regions based on GPS measurements. Geophysical Journal International, 189, 101-122.

Personius, S.F. 2002. Fault number 806, Cottonwood Mountain fault, in Quaternary fault and fold database of the United States. Tech. rept. United States Geological Survey.

Phillips, J. D. 1997a. Potential-field geophysical software for the PC, version 2.2, U.S.G.S. Open-File Report 97-725. Tech. rept. United States Geological Survey.

Phillips, J. D. 1997b. Processing and Interpretation of Aeromagnetic Data for the Santa Cruz Basin Patagonia Mountains Area, South- Central Arizona: U.S. Geological Survey open-file report 02-98. Tech. rept. United States Geological Survey.

Phillips, J. D. 2007. Geosoft eXecutables (GX's) developed by the U.S. Geological Survey, version 2.0, with notes on GX development from FORTRAN code, U.S.G.S. Open-File Report 200\%-1355. Tech. rept. United States Geological Survey.

Price, N.J. 1966. Fault and joint development in brittle and semi-brittle rock. Pergamon Press.

Richards, K., Revil, A., Jardani, A., Henderson, F., Batzle, M., and Haas, A. 2010. Pattern of shallow ground water flow at Mount Princeton Hot Springs, Colorado, using geoelectrical methods. Journal of Volcanology and Geothermal Research, 198(1-2), 217-232. 
Roest, W. R., Verhoett, J., and Pilkington, M. 1992. Magnetic interpretation using the 3-D analytic signal. Geophysics, 57(I), 116-125.

Rosenkjaer, G. K., and Oldenburg, D. W. 2012. 3D INVERSION OF MT DATA IN GEOTHERMAL EXPLORATION : A WORKFLOW AND APPLICATION TO HENGILL, ICELAND. In: Proceedings from the 37th Workshop on Geothermal reservoir Engineering.

Ryan, William B. F., Carbotte, Suzanne M., Coplan, Justin O., O’Hara, Suzanne, Melkonian, Andrew, Arko, Robert, Weissel, Rose Anne, Ferrini, Vicki, Goodwillie, Andrew, Nitsche, Frank, Bonczkowski, Juliet, and Zemsky, Richard. 2009. Global Multi-Resolution Topography synthesis. Geochemistry, Geophysics, Geosystems, $\mathbf{1 0}(3), \mathrm{n} / \mathrm{a}-\mathrm{n} / \mathrm{a}$.

Schill, E., Kohl, T., Geiermann, J., Baujard, C., Koch, S., Deckert, H., Munoz, G., and Abdelfettah, Y. 2011. Multi-Disciplinary Prospection Approach for EGS Reservoirs in the German Variscian Basement. Proceedings from the 36th Workshop on Geothermal reservoir Engineering, SGP-TR-191, 1-8.

Shaltry, D., Colwell, C., Liberty, L., and van Wijk, K. 2013. Seismic Investigation of the Neal Hot Springs Geothermal Area. Boise State University Undergaduate Research Conference.

Sheriff, R.E., and Geldart, L.P. 1982. Exploration Seismology. Cambridge University Press.

Shervais, J.W., and Hanan, B.B. 2008. Lithospheric topography, tilted plumes, and the track of the Snake RiverYellowstone hot spot. Tectonics, 27(5), 1-17. 
Syberg, F.J.R. 1972. A Fourier method for the regional-residual problem of potential fields. Geophysical Prospecting, 20, 47-75.

Telford, W.W.M., Geldart, L.P., and Sheriff, R.E. 1990. Applied Geophysics. Monograph series. Cambridge University Press.

Tester, J. W., Anderson, B., Batchelor, A., Blackwell, D., DiPippo, R., Drake, E., Garnish, J., Livesay, B., Moore, M.C., Nichols, K., Petty, S., Toksoz, N., Veatch, R., Augustine, C., Baria, R., Murphy, E., Negraru, P., and Richards, M. 2006. The Future of Geothermal Energy. Tech. rept. Massachusetts Institute of Technology.

Wisian, K.W., and Blackwell, D.D. 2004. Numerical modeling of Basin and Range geothermal systems. Geothermics, 33, 713-741.

Wisian, K.W., Blackwell, D.D., and Richards, M. 2000. Heat Flow in the Western United States and Extensional Geothermal Systems. In: Twenty-Fourth Workshop on Geothermal Reservoir Engineering.

Wood, S.H., and Clemens, D.M. 2002. Geologic and Tectonic History of the Western Snake River Plain, Idaho and Oregon. Idaho Geological Survey Bulletin, 30, 69-103.

Yilmaz, O. 2001. Seismic Data Analysis. Society of Exploration Geophysics.

Zoback, M.L., and Thompson, G.A. 1978. Basin and Range rifting in northern Nevada: Clues from a mid-Miocene rift and its subsequent offsets. Geology, 6(2), 111.

Zoback, M.L., McKee, E.H., Blakely, R.J., and Thompson, G.A. 1994. The northern Nevada rift: Regional tectono-magmatic relations and middle Miocene stress direction. Geological Society of America Bulletin, 106, 371-382. 
Zonge, K., and Hughes, L. 1991. Controlled Source Audio-Frequency Magnetotellurics. Chap. 9, pages 713-809 of: Electromagnetic Methods in applied Geophysics. Society of Exploration Geophysicists. 
Zonge, K., and Hughes, L. 1991. Controlled Source Audio-Frequency Magnetotellurics. Chap. 9, pages 713-809 of: Electromagnetic Methods in applied Geophysics. Society of Exploration Geophysicists. 
Zonge, K., and Hughes, L. 1991. Controlled Source Audio-Frequency Magnetotellurics. Chap. 9, pages 713-809 of: Electromagnetic Methods in applied Geophysics. Society of Exploration Geophysicists. 
Zonge, K., and Hughes, L. 1991. Controlled Source Audio-Frequency Magnetotellurics. Chap. 9, pages 713-809 of: Electromagnetic Methods in applied Geophysics. Society of Exploration Geophysicists. 
Zonge, K., and Hughes, L. 1991. Controlled Source Audio-Frequency Magnetotellurics. Chap. 9, pages 713-809 of: Electromagnetic Methods in applied Geophysics. Society of Exploration Geophysicists. 
Zonge, K., and Hughes, L. 1991. Controlled Source Audio-Frequency Magnetotellurics. Chap. 9, pages 713-809 of: Electromagnetic Methods in applied Geophysics. Society of Exploration Geophysicists. 
Zonge, K., and Hughes, L. 1991. Controlled Source Audio-Frequency Magnetotellurics. Chap. 9, pages 713-809 of: Electromagnetic Methods in applied Geophysics. Society of Exploration Geophysicists. 
Zonge, K., and Hughes, L. 1991. Controlled Source Audio-Frequency Magnetotellurics. Chap. 9, pages 713-809 of: Electromagnetic Methods in applied Geophysics. Society of Exploration Geophysicists. 
Zonge, K., and Hughes, L. 1991. Controlled Source Audio-Frequency Magnetotellurics. Chap. 9, pages 713-809 of: Electromagnetic Methods in applied Geophysics. Society of Exploration Geophysicists. 
Zonge, K., and Hughes, L. 1991. Controlled Source Audio-Frequency Magnetotellurics. Chap. 9, pages 713-809 of: Electromagnetic Methods in applied Geophysics. Society of Exploration Geophysicists. 
Zonge, K., and Hughes, L. 1991. Controlled Source Audio-Frequency Magnetotellurics. Chap. 9, pages 713-809 of: Electromagnetic Methods in applied Geophysics. Society of Exploration Geophysicists. 